\title{
Coated Fiber Neutron Detector Test
}

\author{
AT Lintereur \\ JH Ely \\ RT Kouzes \\ DC Stromswold
}

October 22, 2009

\section{Pacific Northwest}

NATIONAL LABORATORY

Proudly Operated by Battelle Since 1965 


\title{
DISCLAIMER
}

This report was prepared as an account of work sponsored by an agency of the United States Government. Neither the United States Government nor any agency thereof, nor Battelle Memorial Institute, nor any of their employees, makes any warranty, express or implied, or assumes any legal liability or responsibility for the accuracy, completeness, or usefulness of any information, apparatus, product, or process disclosed, or represents that its use would not infringe privately owned rights. Reference herein to any specific commercial product, process, or service by trade name, trademark, manufacturer, or otherwise does not necessarily constitute or imply its endorsement, recommendation, or favoring by the United States Government or any agency thereof, or Battelle Memorial Institute. The views and opinions of authors expressed herein do not necessarily state or reflect those of the United States Government or any agency thereof.

\author{
PACIFIC NORTHWEST NATIONAL LABORATORY \\ operated by \\ BATTELLE \\ for the \\ UNITED STATES DEPARTMENT OF ENERGY \\ under Contract DE-AC05-76RL01830
}

Printed in the United States of America
Available to DOE and DOE contractors from the Office of Scientific and Technical Information,
P.O. Box 62, Oak Ridge, TN 37831-0062;
ph: (865) 576-8401
fax: $(865)$ 576-5728
email: reports@adonis.osti.gov

\begin{abstract}
Available to the public from the National Technical Information Service, U.S. Department of Commerce, 5285 Port Royal Rd., Springfield, VA 22161 ph: (800) 553-6847 fax: $(703) 605-6900$ email: orders@ntis.fedworld.gov online ordering: http://www.ntis.gov/ordering.htm
\end{abstract}

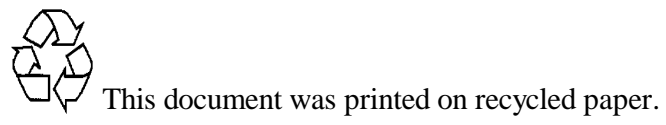


PNNL-18919

\title{
Coated Fiber Neutron Detector Test
}

\author{
AT Lintereur \\ JH Ely \\ RT Kouzes \\ DC Stromswold
}

October 22, 2009

Pacific Northwest National Laboratory

Richland, Washington 99352 


\section{Executive Summary}

Radiation portal monitors used for interdiction of illicit materials at borders include highly sensitive neutron detection systems. The main reason for having neutron detection capability is to detect fission neutrons from plutonium. The currently deployed radiation portal monitors (RPMs) from Ludlum and Science Applications International Corporation (SAIC) use neutron detectors based upon ${ }^{3} \mathrm{He}$-filled gas proportional counters, which are the most common large neutron detector. There is a declining supply of ${ }^{3} \mathrm{He}$ in the world, and thus, methods to reduce the use of this gas in RPMs with minimal changes to the current system designs and sensitivity to cargo-borne neutrons are being investigated.

Four technologies have been identified as being currently commercially available, potential alternative neutron detectors to replace the use of ${ }^{3} \mathrm{He}$ in RPMs. These technologies are:

1) Boron trifluoride $\left(\mathrm{BF}_{3}\right)$-filled proportional counters,

2) Boron-lined proportional counters,

3) Lithium-loaded glass fibers, and

4) Coated non-scintillating plastic fibers.

Reported here are the results of tests of the ${ }^{6} \mathrm{Li} / \mathrm{ZnS}(\mathrm{Ag})$-coated non-scintillating plastic fibers option. This testing measured the required performance for neutron detection efficiency and gamma ray rejection capabilities of a system manufactured by Innovative American Technology (IAT).

Results indicate that an IAT neutron detector with an active surface area of $0.32 \mathrm{~m}^{2}$ (compared to the area of $0.06 \mathrm{~m}^{2}$ for the system tested) would have the same neutron detection efficiency as a single ${ }^{3} \mathrm{He}$ tube in the current standard ${ }^{3} \mathrm{He}$-based polyethylene moderator box, assuming linear scaling with active area. Dynamic tests with the IAT neutron detector demonstrate that with the current temporal resolution the IAT system has a lower efficiency by a factor of two with a moving source than with a static source, since it is designed for static acquisitions and thus is not optimized for short scan times such as are used for dynamic testing. The dynamic efficiency should improve with revised software.

The intrinsic gamma ray efficiency (rejection factor) was found to be on the order of $10^{-7}$ at an exposure rate up to $40 \mathrm{mR} / \mathrm{hr}$ from an ${ }^{192} \mathrm{Ir}$ source, which is the same order of magnitude as what was found for a ${ }^{3} \mathrm{He}$ based system. For exposure rates up to $40 \mathrm{mR} / \mathrm{hr}$ from a ${ }^{60} \mathrm{Co}$ source, the intrinsic gamma ray efficiency is on the order of $10^{-6}$ or better, and thus meets this requirement for the system tested.

The Gamma Absolute Rejection Ratio in the presence of neutrons (GARRn) at $10 \mathrm{mR} / \mathrm{hr}$ is within one standard deviation of the desired range, indicating that there is some miscounting of neutrons in the presence of large gamma exposure rates.

Ship effect (neutron spallation events caused by cosmic rays in a material near the detector) measurements were made by recording the increase in the neutron count rate when a crate of lead was placed near the detector. Simultaneous neutron pulses were recorded using the "oscope" feature of the system.

The system tested demonstrates that this technology could meet the RPMP neutron detection requirements, but testing of a larger detector is required. 


\section{Acronyms and Abbreviations}

ANSI

ASP

Atm

CBP

Cps

DOE

GARRn

IAT

MCNP

PNNL

PolyBox

POV

PVT

RPM

RSP

SAIC
American National Standards Institute

Advanced Spectroscopic Portal

atmospheres

Customs and Border Protection

counts per second

U.S. Department of Energy

Gamma Absolute Rejection Ratio in the presence of neutrons

Innovative American Technologies

Monte Carlo for Neutrons and Photons Transport Code

Pacific Northwest National Laboratory

polyethylene moderator/reflector box

personally owned vehicle

Polyvinyl Toluene (plastic) scintillation gamma detector

Radiation Portal Monitor

Radiation Sensor Panel

Science Applications International Corporation 


\section{Contents}

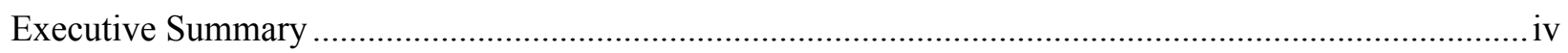

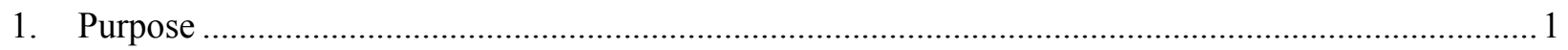

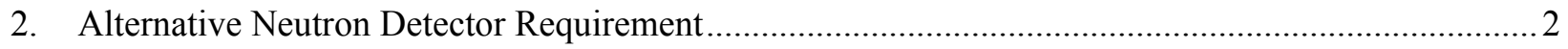

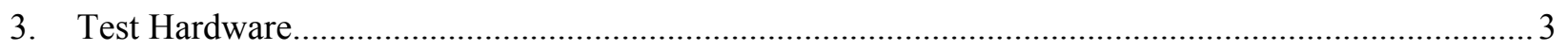

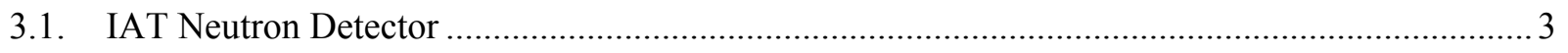

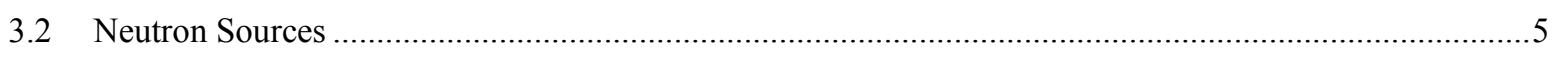

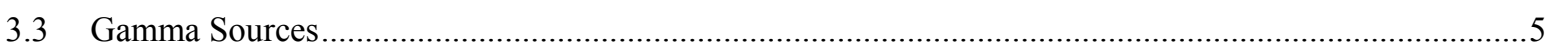

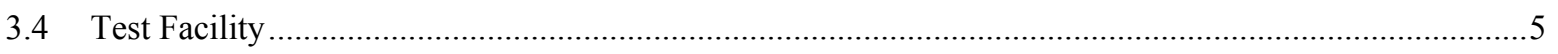

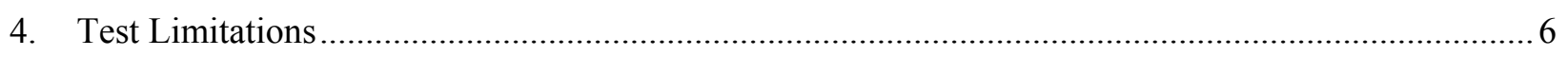

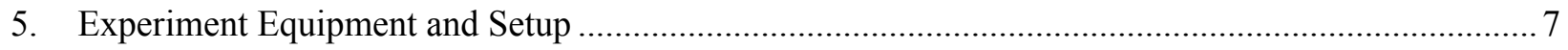

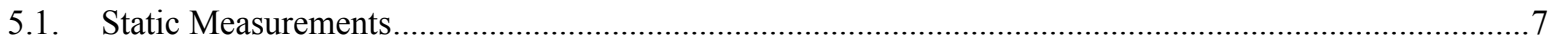

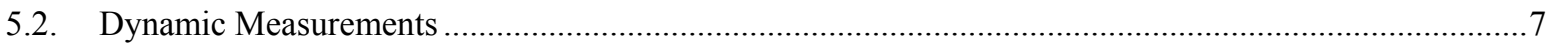

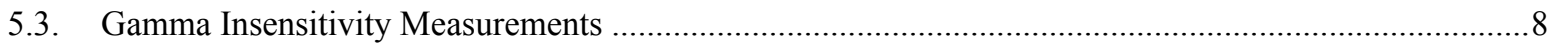

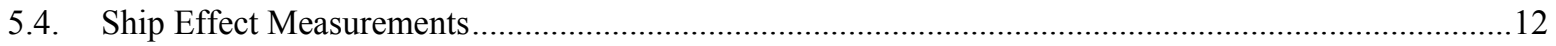

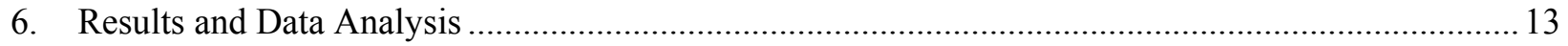

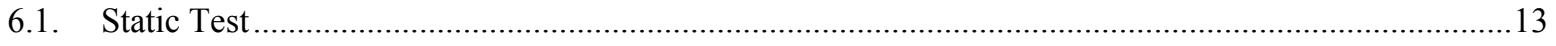

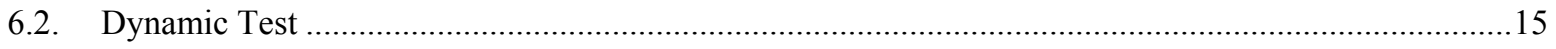

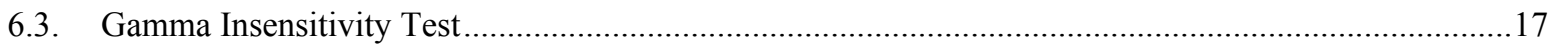

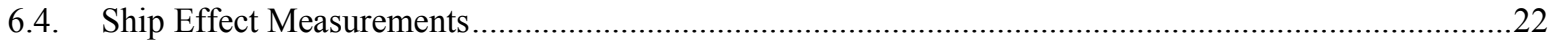

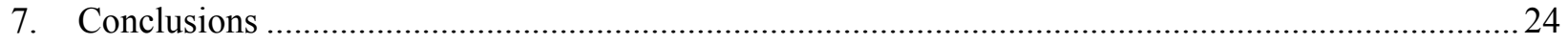

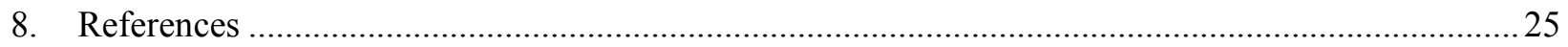




\section{Figures and Tables}

\section{Figures}

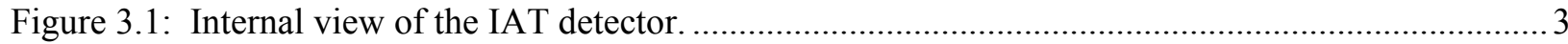

Figure 3.2: IAT detector setup with tripod for source placement......................................................... 4

Figure 3.3: Neutron (left) and gamma (right) pulse shapes. ............................................................. 4

Figure 5.1: Shuttle track used to move the moderated and bare neutron source past the detector. .............. 8

Figure 5.2: The IAT detector positioned for gamma insensitivity testing with the ${ }^{192}$ Ir source. ................. 9

Figure 5.3: The ${ }^{192} \mathrm{Ir}$ source positioned behind the concrete block. ...................................................... 10

Figure 5.4: Source positioned near detector for neutron measurements in a high gamma field................ 10

Figure 5.5: IAT detector positioned in the Radiological Calibration Laboratory..................................... 11

Figure 5.6: IAT detector positioned to be exposed to both the ${ }^{252} \mathrm{Cf}$ source and the ${ }^{60} \mathrm{Co}$ source in the

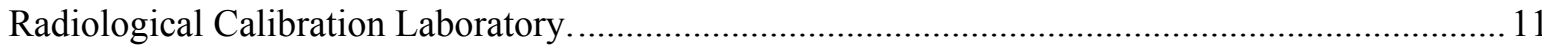

Figure 5.7: IAT detector and positioned next to lead bricks for ship effect measurements..................... 12

Figure 6.1: Average cps for the two original detector moderation configurations, 38 and $51 \mathrm{~mm}$, with both

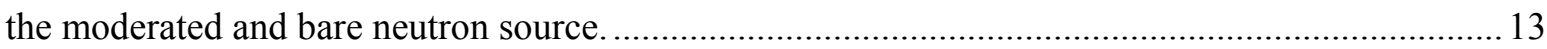

Figure 6.2: Net cps with the moderated and bare neutron source for varying amounts of moderation. ..... 14

Figure 6.3: Detector efficiency shown both for the system tested and scaled by a factor of 5 compared to

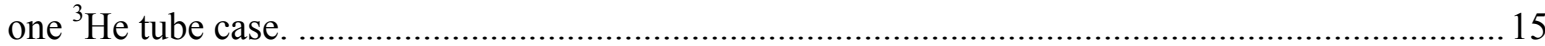

Figure 6.4: Five mph $(2.2 \mathrm{~m} / \mathrm{s})$ temporal spectra acquired with the moderated source. The ${ }^{3} \mathrm{He}$ data is summed into 1 -second segments and the IAT data is scaled for geometry...................................... 16

Figure 6.5: Two mph $(0.9 \mathrm{~m} / \mathrm{s})$ temporal spectra acquired with the moderated source. The ${ }^{3} \mathrm{He}$ counts are summed into 1-second time intervals and the IAT counts are scaled for geometry.

Figure 6.6: Detector response to gamma ray sources placed on the detector housing. 18

Figure 6.7: Detector response to neutrons when the ${ }^{60} \mathrm{Co}$ source was placed directly on the detector housing.

Figure 6.8: Pulse height spectra of the IAT neutron detector in response to a neutron source and a gamma field of different exposure rates compared to the pulse height spectra from a neutron source without the gamma source.

Figure 6.9: Simultaneously recorded double neutron event (a) and triple neutron event (b) due to the ship effect. Images recorded using the IAT Oscope software. 


\section{Tables}

Table 5.1: Exposure rate versus distance for the $18 \mathrm{Ci}^{192} \mathrm{Ir}$ source...................................................

Table 5.2: Exposure rate versus distance for the ${ }^{60} \mathrm{Co}$ source................................................................. 12

Table 6.1: Exposure rates on the detector from the gamma sources used for location specific gamma-ray

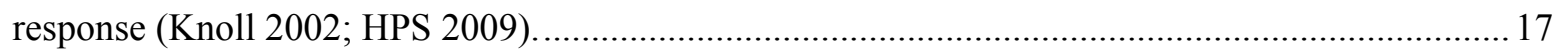

Table 6.2: Neutron counts recorded in the presence of a high exposure rate gamma field from ${ }^{192} \mathrm{Ir} . . . . . . .19$

Table 6.3: Estimated number of ${ }^{192}$ Ir photons incident on the active area of the detector calculated using both the source strength and an effective activity for each of the exposure rates. ...........................20

Table 6.4: Neutron counts recorded in the presence of a high exposure rate ${ }^{60} \mathrm{Co}$ gamma field. ...............2 21

Table 6.5: Estimated number of photons incident on the active area of the detector calculated using the

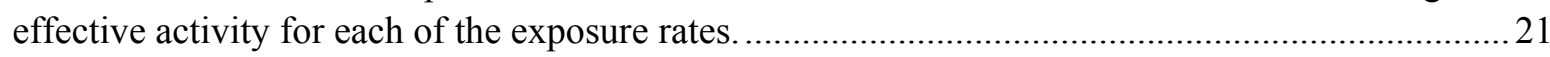

Table 6.6: Estimates of the Absolute Efficiency, GARRn and the Intrinsic Gamma Ray Rejection Factor for the different gamma exposure rates for the small detector tested............................................... 22 


\section{Purpose}

Radiation portal monitor (RPM) systems used for interdiction of illicit materials at borders include highly sensitive neutron detection systems. The main reason for having neutron detection capability is to detect fission neutrons from plutonium. The currently deployed radiation portal monitors from Ludlum and Science Applications International Corporation (SAIC) use neutron detectors based upon ${ }^{3} \mathrm{He}$-filled gas proportional counters, which are the most common large neutron detector.

Within the last few years, the amount of ${ }^{3} \mathrm{He}$ available for use in gas proportional counter neutron detectors has become more restricted, while the demand has significantly increased, especially for homeland security applications (Kouzes 2009). In the near future, limited supply is expected to curtail the use of ${ }^{3} \mathrm{He}$; therefore, alternative neutron detection technologies are being investigated for use in the radiation portal monitor systems being deployed for border security applications (Van Ginhoven 2009).

From a survey of technologies, only four technologies have been identified as currently commercially available, potential alternative neutron detectors to replace the use of ${ }^{3} \mathrm{He}$ in RPMs in the near-term. These technologies are:

1) Boron trifluoride $\left(\mathrm{BF}_{3}\right)$-filled proportional counters (from Reuter Stokes or LND),

2) Boron-lined proportional counters (from Reuter Stokes or LND),

3) Lithium-loaded glass fibers (from NucSafe), and

4) Coated non-scintillating plastic fibers (from Innovative American Technology [IAT]).

Reported here are the results of tests of the ${ }^{6} \mathrm{Li} / \mathrm{ZnS}(\mathrm{Ag})$-coated non-scintillating plastic fibers option. The testing measured the neutron detection efficiency and gamma ray rejection capabilities of a system manufactured by IAT. The purpose of this testing was to measure the efficiency of the IAT neutron detection system to determine if this technology can meet the specified neutron detection requirements. The ability of the "oscope" software feature to be used to make ship effect measurements was also tested. The measurements made as part of this testing included:

1) Response of the system to moderated and un-moderated neutrons with the original detector moderation configuration

2) Response of the system to moderated and un-moderated neutrons with varying amounts of detector moderation

3) Response of the system to gamma-ray sources placed on the detector housing at specific locations

4) Response of the system to a high gamma-ray exposure rate to measure gamma sensitivity and GARRn (Kouzes et al., 2009)

5) Dynamic measurements with the original detector moderation made with the moderated and unmoderated neutron source

6) Response of the system to ship effect events caused by a crate of lead being placed near the detector. 


\section{Alternative Neutron Detector Requirement}

Coated non-scintillating plastic fibers are a possible neutron detector replacement technology for ${ }^{3} \mathrm{He}-$ filled tubes. These fibers can be fashioned in dimensions that will fit in the space available in the currently deployed standard ${ }^{3} \mathrm{He}$-based RPM polyethylene box [0.114 m deep x $0.304 \mathrm{~m}$ wide x $2.18 \mathrm{~m}$ tall (4.5 in. $\times 12$ in. $\times 85.7$ in.)] that contains the ${ }^{3} \mathrm{He}$ tubes. However, the largest IAT plastic fiber detector size currently available has an active detection area of $0.25 \mathrm{~m} \mathrm{x} 0.25 \mathrm{~m}$ (10 in. x $10 \mathrm{in}$.)

Pacific Northwest National Laboratory (PNNL) has tested the IAT neutron detection system. The dimensions of the active volume of the IAT system tested are $0.25 \mathrm{~m} \times 0.25 \mathrm{~m} \times 0.10 \mathrm{~m}$ of polyethylene sandwiched around the fiber detectors. A system for replacement of the current neutron detectors in a standard ${ }^{3} \mathrm{He}$-based RPM must fit within the space occupied by the present ${ }^{3} \mathrm{He}$-based neutron detection system.

The standard ${ }^{3} \mathrm{He}$-based systems were purchased under a specification (Stromswold et al., 2003) that requires a single radiation sensor panel (RSP) to meet the following requirements:

"A ${ }^{252} \mathrm{Cf}$ neutron source will be used for testing neutron sensor sensitivity:

- To reduce the gamma-ray flux, the source shall be surrounded by at least $0.5 \mathrm{~cm}$ of lead. To moderate the neutron spectrum, $2.5 \mathrm{~cm}$ of polyethylene shall be placed around the source.

- The absolute detection efficiency for such a ${ }^{252} \mathrm{Cf}$ source, located $2 \mathrm{~m}$ perpendicular to the geometric midpoint of the neutron sensor, shall be greater than $2.5 \mathrm{cps} / \mathrm{ng}$ of ${ }^{252} \mathrm{Cf}$. The neutron detector center shall be $1.5 \mathrm{~m}$ above grade for this test. (Note: 10 nanograms of ${ }^{252} \mathrm{Cf}$ is equivalent to 5.4 micro-Ci or $2.1 \times 10^{4} \mathrm{n} / \mathrm{s},{ }^{1}$ since ${ }^{252} \mathrm{Cf}$ has a $3.092 \%$ spontaneous fission $(\mathrm{SF})$ branch and 3.757 neutrons/SF.)

- The neutron detector shall not generate alarms due to the presence of strong gamma-ray sources. The ratio of neutron sensor gamma-ray detection efficiency to neutron detection shall be less than 0.001."

To evaluate the performance of alternate neutron detectors compared to what is currently deployed three criteria are considered: 1) absolute neutron detection efficiency, 2) intrinsic efficiency of gammas detected as neutrons, and 3) Gamma Absolute Rejection Ratio in the presence of neutrons (GARRn) (Kouzes et al., 2009).

The absolute neutron detection efficiency $\left(\epsilon_{\mathrm{abs} n}\right)$ required is that previously specified $(2.5 \mathrm{cps} / \mathrm{ng}$ from a ${ }^{252} \mathrm{Cf}$ source at $2 \mathrm{~m}$ in a specified pig). The intrinsic efficiency of gammas detected as neutrons $\left(\epsilon_{\mathrm{int}} \gamma \mathrm{n}\right)$ is the number of events that are counted as neutrons in the presence of a gamma source divided by the number of photons hitting the detector area, and shall be less than $10^{-6}$ at an exposure rate of $10 \mathrm{mR} / \mathrm{h}$. GARRn is the number of events that are counted as neutrons $\left(\epsilon_{\mathrm{abs} \gamma \mathrm{n}}\right)$ in the presence of both a gamma and neutron source divided by the number of neutrons recorded without the gamma source $\left(\epsilon_{\mathrm{abs}}\right)$, the requirement for this parameter is that $0.9 \leq \mathrm{GARRn} \leq 1.1$ at a $10 \mathrm{mR} / \mathrm{h}$ gamma exposure rate.

In addition, these systems are required to meet all aspects of the ANSI N42.35 standard (ANSI 2004). A summary of neutron detection systems in RPMs can be found in a PNNL report (Kouzes et al., 2007).

\footnotetext{
${ }^{1} 2.3 \times 10^{4} \mathrm{n} / \mathrm{s}$ is the currently used best known value
} 


\section{Test Hardware}

\subsection{IAT Neutron Detector}

The IAT neutron detector uses non-scintillating plastic fibers (BC-704 from Saint Gobain) that are coated with ${ }^{6} \mathrm{Li} / \mathrm{ZnS}(\mathrm{Ag})$. The fibers are arranged side-by-side and the detector has four layers of fibers. The active width (coated) of the fiber array is $0.25 \mathrm{~m}$ and the active length is $0.25 \mathrm{~m}$. Fibers extend beyond the $0.25 \mathrm{~m}$ active length and are bundled at both ends into $0.05-\mathrm{m}$-diameter photomultiplier tubes. Figure 3.1 shows the (black) fiber array covered by the polyethylene moderator and the photomultiplier tubes.

The ${ }^{6} \mathrm{Li} / \mathrm{ZnS}(\mathrm{Ag})$ serves as neutron absorber and phosphor. Thermal neutrons interact via the ${ }^{6} \mathrm{Li}(\mathrm{n}, \alpha)^{3} \mathrm{H}$ reaction, and the resultant charged particles produce light in the zinc sulfide. The plastic wavelength shifting fibers conduct the light to the photomultiplier tubes.

On one side of the fiber array the polyethylene is $0.25 \mathrm{~m} \mathrm{x} 0.25 \mathrm{~m} \mathrm{x} 0.05-\mathrm{m}$ (2-inch) thick and on the other side it is $0.25 \mathrm{~m} \times 0.25 \mathrm{~m} \times 0.38-\mathrm{m}$ (1.5-inch) thick. Separate tests were conducted with a neutron source facing each of the polyethylene sides, as well as tests with the $0.05-\mathrm{m}$-thick polyethylene removed and thinner sheets substituted. The system in position for testing is seen in Figure 3.2.

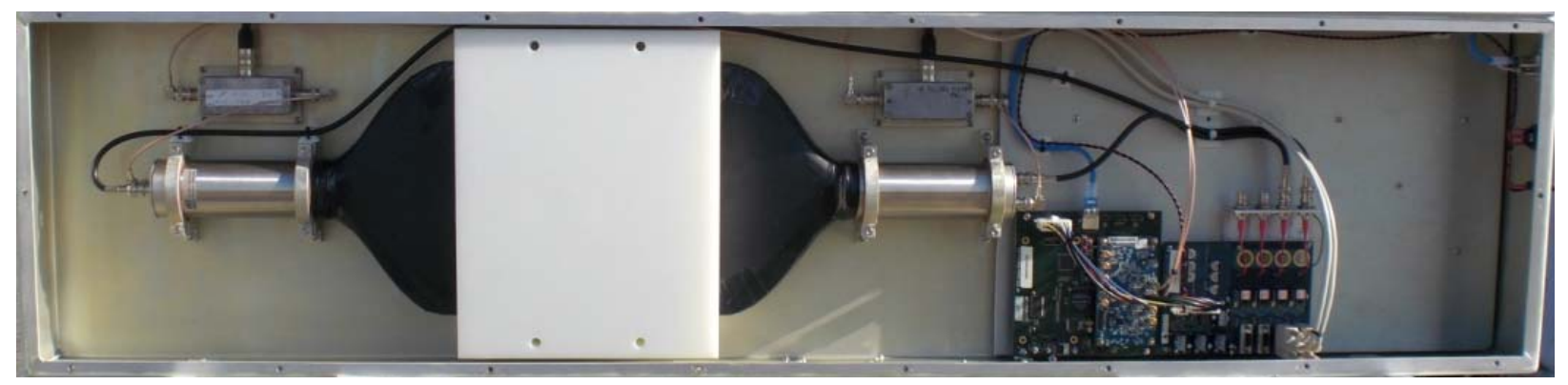

Figure 3.1: Internal view of the IAT detector. 


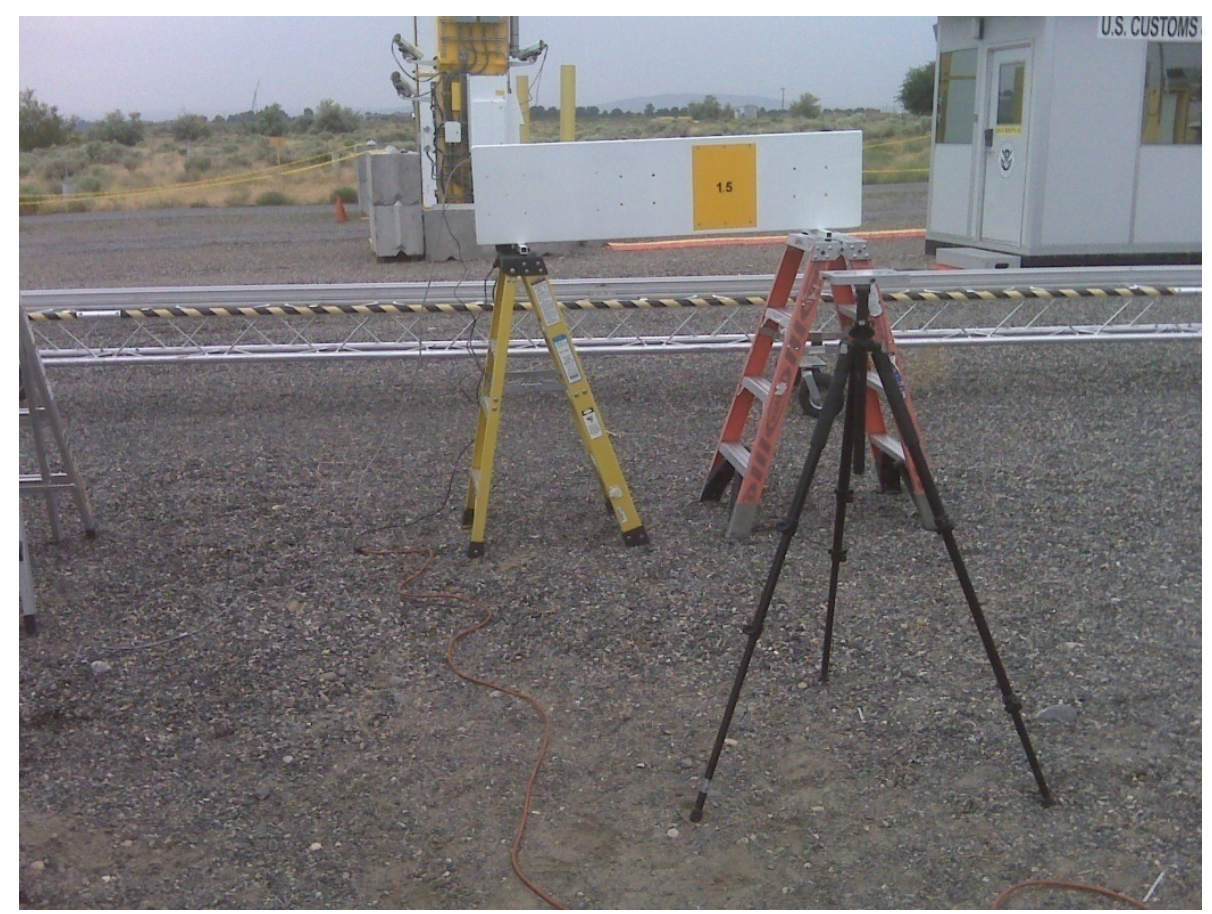

Figure 3.2: IAT detector setup with tripod for source placement.

The electronics for the detector (shown in Figure 3.1) process the signals to provide the neutron count rate. Signals from both photomultiplier tubes are digitized separately, and pulse-shape analysis yields discrimination between neutron and gamma ray pulses. Figure 3.3 shows an example trace of both a neutron and a gamma ray interaction. Gamma ray pulses are narrower than neutron pulses (neutron pulses have a longer fall time) and have a faster rise time as calculated by averaging over several channels at the beginning of individual pulses.

Counts identified as "neutrons" are recorded by the two-photomultiplier tubes and converted to count rate. The average count rate can be found by summing the output from each PMT and dividing by two (since the majority of pulses are observed in both PMTs). Pulses identified as "gamma rays" are discarded and not tabulated in the present software.

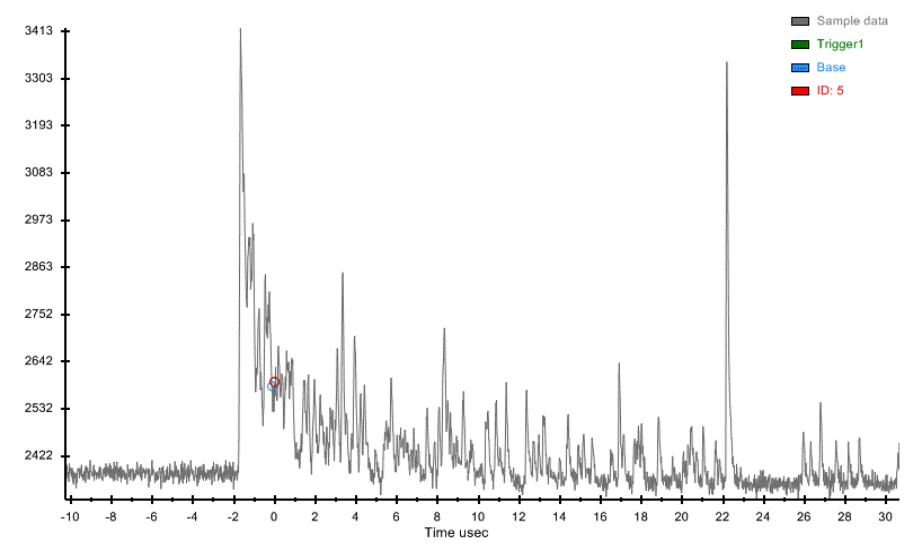

Figure 3.3: Neutron (left) and gamma (right) pulse shapes. 


\subsection{Neutron Sources}

The two neutron sources used for this test were both ${ }^{252} \mathrm{Cf}$. The sources were purchased from Isotope Products Laboratory (IPL) and given PNNL IDs of 60208-16 and 56595-130B. The sources were measured by IPL to be $20 \pm 3 \mu \mathrm{Ci}$ on February 15, 2009 and $20 \pm 3 \mu \mathrm{Ci}$ on December 15, 2003, respectively. The source compositions were $93.832 \%{ }^{252} \mathrm{Cf}, 0.0309 \%{ }^{251} \mathrm{Cf}, 6.016 \%{ }^{250} \mathrm{Cf}$, and $0.117 \%$ ${ }^{249} \mathrm{Cf}$ and $93.832 \%{ }^{252} \mathrm{Cf}, 0.0309 \%{ }^{251} \mathrm{Cf}, 6.016 \%{ }^{250} \mathrm{Cf}$, and $0.117 \%{ }^{249} \mathrm{Cf}$ respectively, according to IPL. Using these values, the two sources used were estimated to be 17.68 and $4.5 \mu \mathrm{Ci}$ on the dates of the testing. These activities correspond to estimated emanation rates of $6.88 \times 10^{4} \mathrm{n} / \mathrm{s}$ and $1.75 \times 10^{4} \mathrm{n} / \mathrm{s}$ respectively using the conversion factor stated in Section 2.

The $17.68 \mu \mathrm{Ci}$ source was used in two configurations; 1$)$ moderated ( $25 \mathrm{~mm}$ of polyethylene moderator outside of $5 \mathrm{~mm}$ of lead) and 2) bare (encased only in the source's own stainless steel enclosure). For the static tests, the source was placed on a tripod. For the dynamic tests, the source was placed on a shuttle track that moved the source past the detector at a constant speed. The gamma insensitivity measurements performed with ${ }^{60} \mathrm{Co}$ source used the $17.68 \mu \mathrm{Ci}$ neutron source in its moderated configuration only. The $4.5 \mu \mathrm{Ci}$ source was used for the gamma insensitivity tests with the ${ }^{192} \mathrm{Ir}$ source, and was used in its moderated form only.

\subsection{Gamma Sources}

Four gamma sources $\left({ }^{109} \mathrm{Cd},{ }^{192} \mathrm{Ir}\right.$ and two different ${ }^{60} \mathrm{Co}$ sources) were used in these measurements. Two of the sources, one of the ${ }^{60} \mathrm{Co}$ sources and the ${ }^{109} \mathrm{Cd}$ source were purchased from IPL by PNNL and given PNNL IDs of 1103-29-2 and 6013-5-2, respectively. The ${ }^{60} \mathrm{Co}$ source was measured by IPL to have an activity of $110 \mu \mathrm{Ci}$ on March 15,2005 . The ${ }^{109} \mathrm{Cd}$ source had an activity of $2 \mathrm{mCi}$ as measured by IPL on June 15, 2009. Using these values the ${ }^{60} \mathrm{Co}$ source strength was calculated to be $61.69 \mu \mathrm{Ci}$ and the ${ }^{109} \mathrm{Cd}$ source strength was calculated to be $1.85 \mathrm{mCi}$ on the day of the static tests. The third source, an ${ }^{192} \mathrm{Ir}$ commercial radiography source, was supplied by Northwest Inspections and reported to have an activity of $18 \mathrm{Ci}$ on August 24, 2009. The exposure rate at the detector from the ${ }^{192} \mathrm{Ir}$ source was measured with a calibrated meter. The last source used was the ${ }^{60} \mathrm{Co}$ source located in the Radiological Calibrations Laboratory in Building 318 at PNNL. The exposure rate at the detector from the ${ }^{60} \mathrm{Co}$ source was determined using a calibrated ion chamber.

The small ${ }^{60} \mathrm{Co}$ and ${ }^{109} \mathrm{Cd}$ button sources were used to make localized gamma sensitivity measurements, while the ${ }^{192} \mathrm{Ir}$ and large ${ }^{60} \mathrm{Co}$ source were used to flood the entire detector with a high exposure rate gamma field.

\subsection{Test Facility}

The tests were performed at PNNL at the $331 \mathrm{G}$ Integration Test Facility and the 318 Radiological Calibrations Laboratory located in Richland, WA. The static and dynamic tests were performed at $331 \mathrm{G}$, the static tests on Friday, August 7, 2009, and the dynamic tests on Friday, August 14, 2009. The gamma insensitivity measurements with the ${ }^{192}$ Ir source were performed on Monday, August 24, 2009 at $331 \mathrm{G}$. The ${ }^{60} \mathrm{Co}$ gamma insensitivity measurements were performed at Building 318 on September 15, 2009. 


\section{Test Limitations}

There were several limitations for this test and results may change with different conditions.

- Only one test location for each of the measurements was used, with the corresponding background. Since the testing was focused on net results (background subtracted) this should have little effect on the overall results.

- Only one IAT detector system was tested. Results may change with different detector geometries.

- Uncertainty in the source strength was the main limitation to the test results. 


\section{Experiment Equipment and Setup}

\subsection{Static Measurements}

Static measurements were made first with the original and then with a series of varied detector moderation thicknesses. The detector system was situated so that the center of the detector was $1.37 \mathrm{~m}$ above the ground. The neutron source was located on a tripod $2 \mathrm{~m}$ from the front panel of the detector housing and at a height that positioned the source in the center of the detector.

Data was acquired over 5 minute time intervals with two neutron source configurations. For one configuration the source was located in a polyethylene pig ( $6 \mathrm{~mm}$ of lead and $25 \mathrm{~mm}$ of polyethylene) and for the other configuration the source was used bare. The original moderator arrangement was $38 \mathrm{~mm}$ (1.5 in.) of polyethylene on one side of the detector and $51 \mathrm{~mm}$ (2 in.) of polyethylene on the other side of the detector with the top and bottom of the detector both being covered by $25 \mathrm{~mm}$ (1 in.) of polyethylene. For the altered moderator thicknesses measurements, the $51 \mathrm{~mm}$ polyethylene was removed (the $38 \mathrm{~mm}$ polyethylene on the back of the detector remained the same for all of the tests) and replaced with the following amounts of polyethylene:

1. $0 \mathrm{~mm}$

2. $9.5 \mathrm{~mm}$

3. $19 \mathrm{~mm}$

4. $28.6 \mathrm{~mm}$

5. $38 \mathrm{~mm}$ (the original configuration)

6. $47.6 \mathrm{~mm}$

The static measurements were used to obtain data that allowed the IAT detector efficiency to be compared to the efficiency of the ${ }^{3} \mathrm{He}$ tubes used in the current systems.

\subsection{Dynamic Measurements}

Dynamic measurements were performed to ensure that the temporal profiles from the IAT detector match the profiles from ${ }^{3} \mathrm{He}$. Any significant change in the temporal profile may indicate that changes in the alarm algorithm might be required if plastic fibers are chosen to replace ${ }^{3} \mathrm{He}$.

To make the dynamic measurements the neutron source, in both the moderated and un-moderated configuration, was placed on an automated shuttle track, as shown in Figure 5.1. The center of the track was $1 \mathrm{~m}$ from the front of the detector housing and $1.3 \mathrm{~m}(51 \mathrm{in}$.) off the ground, which placed the center of the source at the same height as the center of the detector. The track moved the source past the detector at the two speeds that correspond to primary and secondary screening, $5 \mathrm{mph}(2.2 \mathrm{~m} / \mathrm{s})$ and 2 $\mathrm{mph}(0.9 \mathrm{~m} / \mathrm{s})$ respectively. 


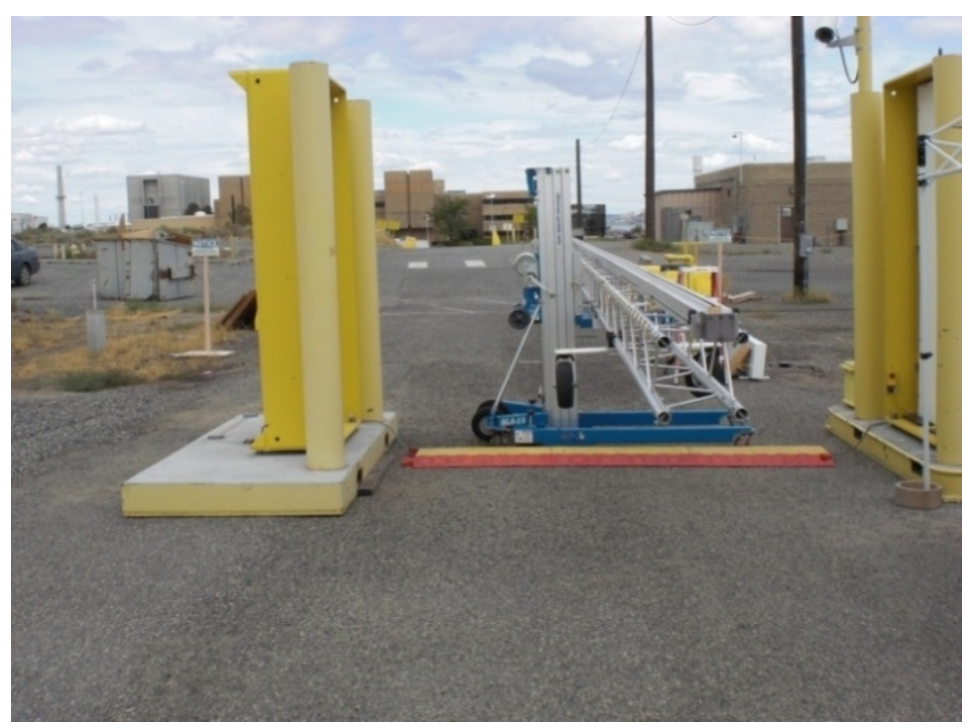

Figure 5.1: Shuttle track used to move the moderated and bare neutron source past the detector.

\subsection{Gamma Insensitivity Measurements}

The detector sensitivity to gamma rays was tested under two different situations. First, both ${ }^{60} \mathrm{Co}$ and ${ }^{109} \mathrm{Cd}$ gamma ray button sources were used in static measurements to check the gamma sensitivity of specific locations on the detector. Second, high-activity ${ }^{192} \operatorname{Ir}$ and ${ }^{60} \mathrm{Co}$ sources were used to flood the entire detector system with a high gamma exposure rate field.

\section{Localized Gamma Insensitivity Measurements}

The ${ }^{60} \mathrm{Co}$ and ${ }^{109} \mathrm{Cd}$ gamma button sources were placed directly on the detector housing in five different locations. Five minute spectra were acquired with each gamma source in the following five positions:

1. Center of the detector on the side with $38 \mathrm{~mm}$ of polyethylene

2. On top of the detector housing

3. To the left of the detector over the fibers on the side with $38 \mathrm{~mm}$ of polyethylene

4. To the right of the detector over the fibers on the side with $38 \mathrm{~mm}$ of polyethylene

5. On the detector fibers

Measurements were also made with the neutron source and the ${ }^{60} \mathrm{Co}$ source on both the 38 -mm and 50mm polyethylene sides of the detector. For these measurements the ${ }^{60} \mathrm{Co}$ source was placed to the left of the detector, over the fibers.

\section{${ }^{192}$ Ir High Exposure Rate Gamma Insensitivity Measurements}

The ${ }^{192}$ Ir gamma-sensitivity measurements were made with the detector placed on ladders with the side containing $38 \mathrm{~mm}$ of polyethylene moderation facing the ${ }^{192} \mathrm{Ir}$ source. The detector was moved different distances away from the source (Figure 5.2) to obtain the exposure rates on the detector's front face when the source was "open" as given in Table 5.1. 


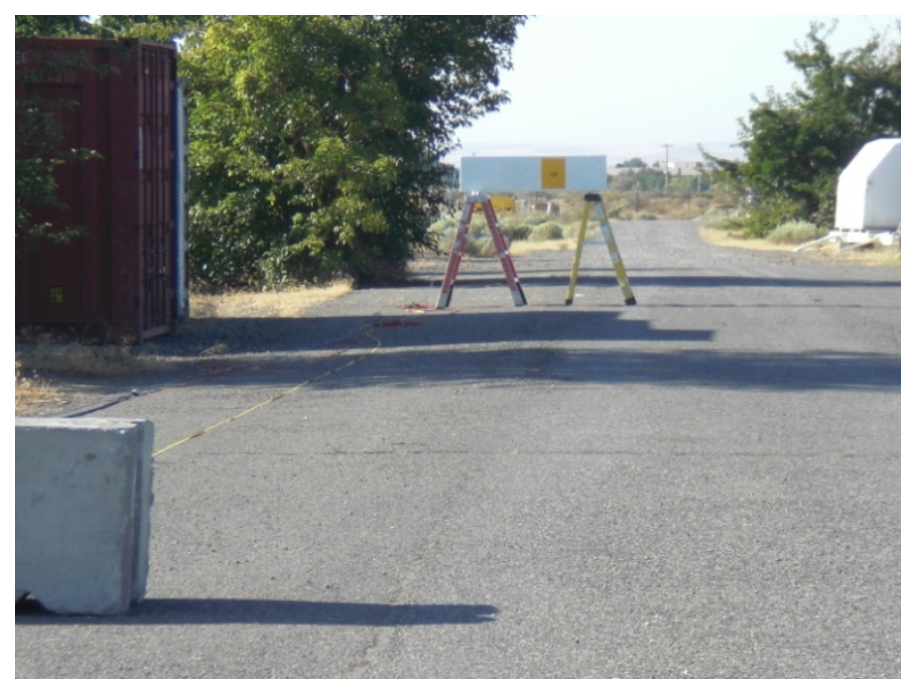

Figure 5.2: The IAT detector positioned for gamma insensitivity testing with the ${ }^{192} \mathrm{Ir}$ source.

Table 5.1: Exposure rate versus distance for the $\mathbf{1 8 ~ C i}{ }^{192}$ Ir source.
\begin{tabular}{|c|c|}
\hline Exposure Rate (mR/h) & Distance (m) \\
\hline 10 & 29.2 \\
\hline 15 & 27.2 \\
\hline 20 & 24.6 \\
\hline 40 & 18.2 \\
\hline 60 & 14.6 \\
\hline 80 & 12.3 \\
\hline 100 & 9.5 \\
\hline 200 & 7.5 \\
\hline
\end{tabular}

The required distances between source and detector were determined by measuring the distance to the source when the appropriate exposure rate was obtained on a rate-meter with the source open. The ratemeter was handled by a PNNL Radiation Control Technician and by Northwest Inspection (source subcontractor). The ${ }^{192}$ Ir source was placed behind a concrete block to decrease the exposure to the testers, as shown in Figure 5.3. Five-minute measurements were made for four different scenarios at each position:

1. Source closed (background)

2. Source open

3. Source open and the $4.5 \mu \mathrm{Ci}$ neutron source located on a tripod $1 \mathrm{~m}$ from the side of the detector with $51 \mathrm{~mm}$ of polyethylene moderation (shown in Figure 5.4).

4. Source closed and the $4.5 \mu \mathrm{Ci}$ neutron source located on a tripod $1 \mathrm{~m}$ from the side of the detector with $51 \mathrm{~mm}$ of polyethylene moderation. 


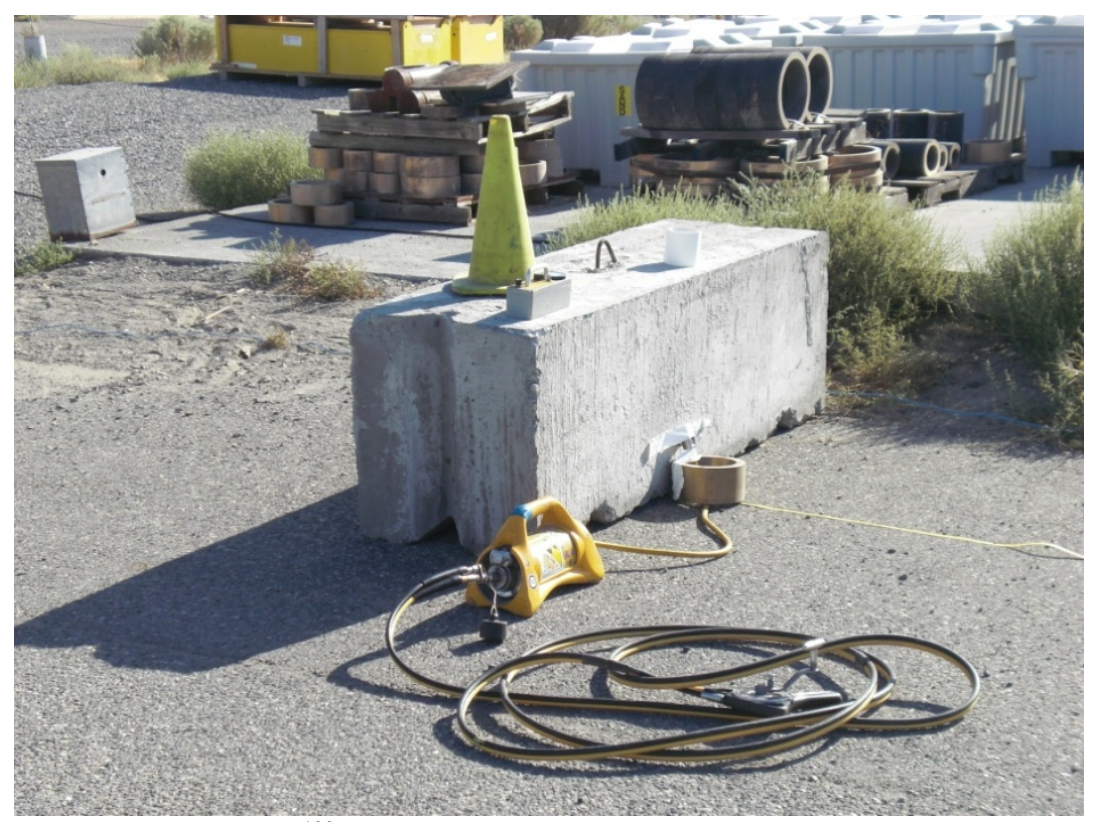

Figure 5.3: The ${ }^{192}$ Ir source positioned behind the concrete block.

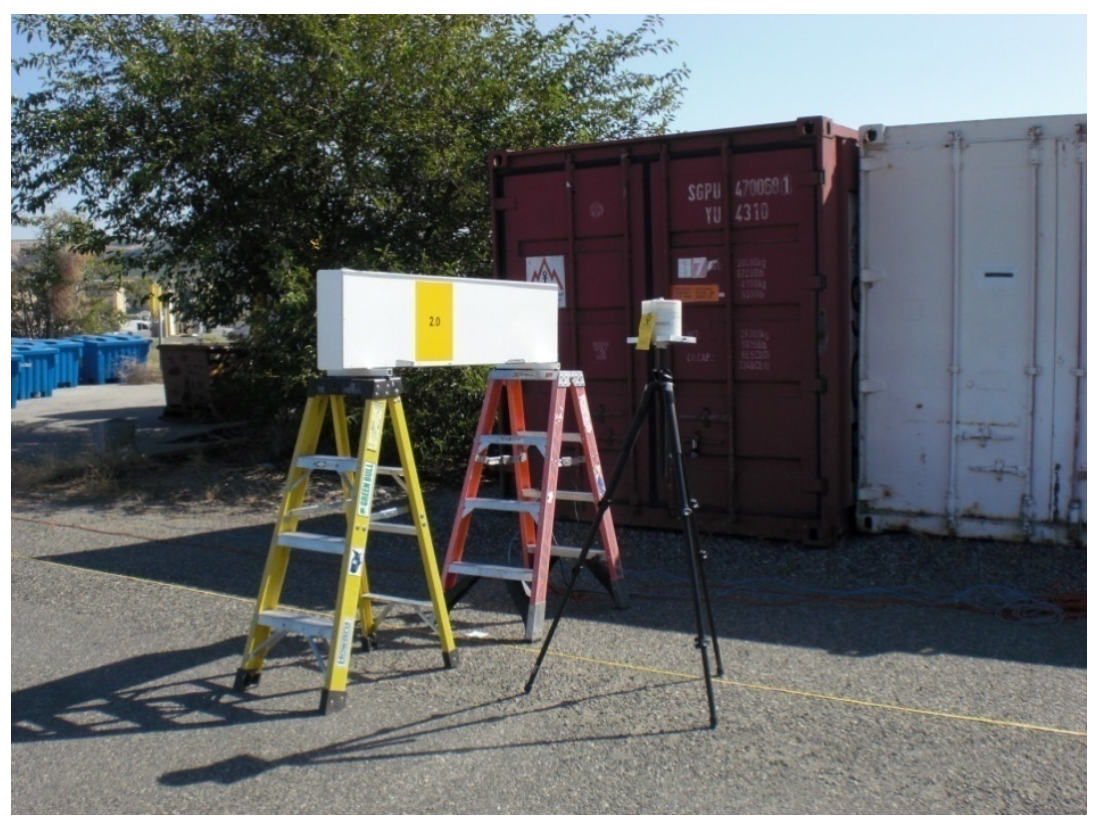

Figure 5.4: Source positioned near detector for neutron measurements in a high gamma field.

\section{${ }^{60}$ Co High Exposure Rate Gamma Insensitivity Measurements}

The ${ }^{60} \mathrm{Co}$ gamma-sensitivity measurements were made with the detector placed on the same ladders as used for the ${ }^{192} \mathrm{Ir}$ source testing with the side containing $38 \mathrm{~mm}$ of polyethylene moderation facing the source, Figure 5.5. 


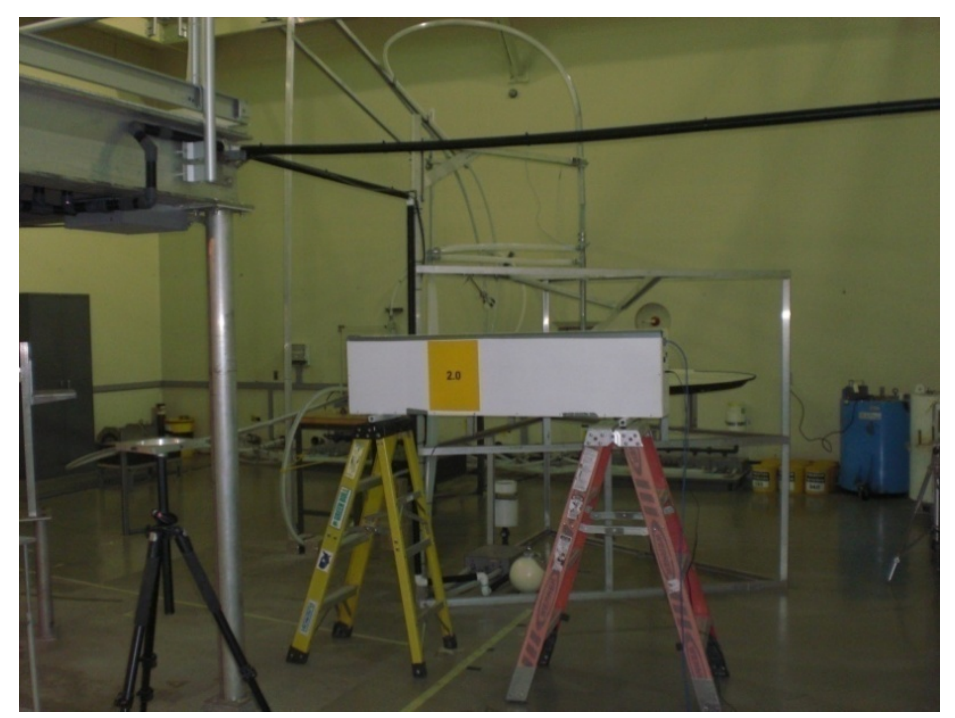

Figure 5.5: IAT detector positioned in the Radiological Calibration Laboratory.

The detector was moved to different distances from the source to obtain the desired exposure rates, Table 5.2 , on the detector's front face when the source was in position. The distances required to achieve the exposure rates used for these measurements were determined by the source handlers. Five minute measurements were made for two different scenarios at each position:

1. ${ }^{60} \mathrm{Co}$ source in place

2. ${ }^{60} \mathrm{Co}$ source in place and the $17.68 \mu \mathrm{Ci}$ neutron source located on a tripod $2 \mathrm{~m}$ from the side of the detector with $51 \mathrm{~mm}$ of polyethylene moderation (shown in Figure 5.6).

A background measurement was made at the start, middle, and end of the data collection period. A measurement with just the $17.68 \mu \mathrm{Ci}^{252} \mathrm{Cf}$ source $2 \mathrm{~m}$ from the side of the detector with $51 \mathrm{~mm}$ of polyethylene was made at the start and in the middle of the other measurements.

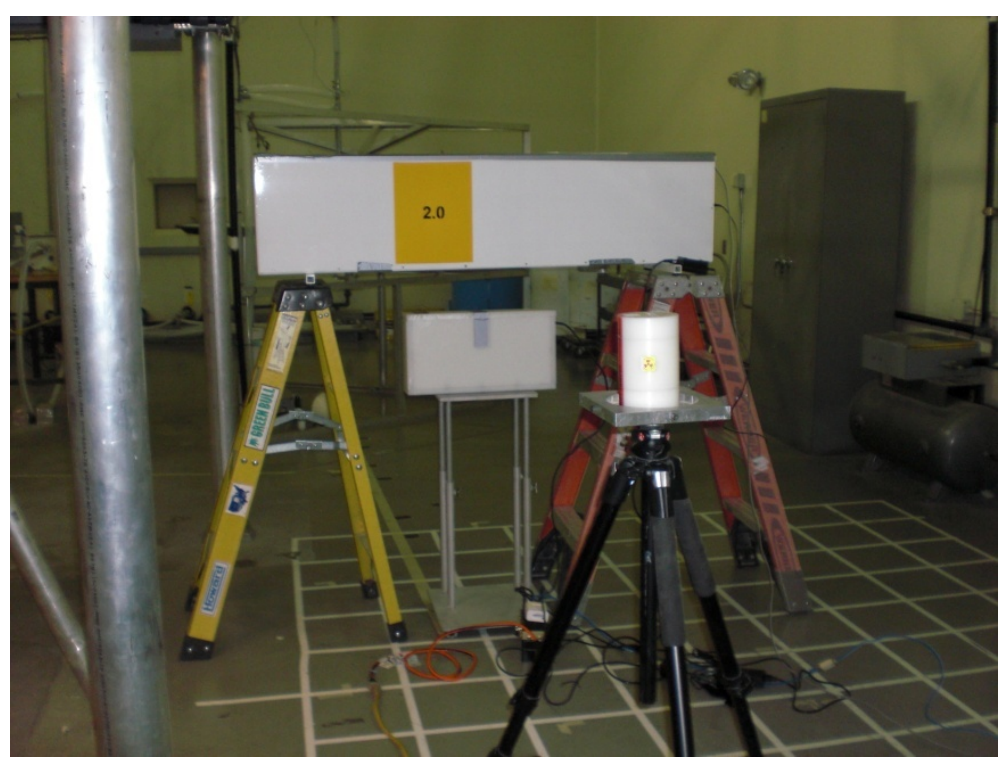

Figure 5.6: IAT detector positioned to be exposed to both the ${ }^{252} \mathrm{Cf}$ source and the ${ }^{60} \mathrm{Co}$ source in the Radiological Calibration Laboratory. 
Table 5.2: Exposure rate versus distance for the ${ }^{60} \mathrm{Co}$ source.

\begin{tabular}{|c|c|}
\hline Exposure Rate (mR/h) & Distance (m) \\
\hline 10 & 3.88 \\
\hline 20 & 2.74 \\
\hline 30 & 2.24 \\
\hline 40 & 1.94 \\
\hline 50 & 1.73 \\
\hline 70 & 1.47 \\
\hline 100 & 1.23 \\
\hline
\end{tabular}

\subsection{Ship Effect Measurements}

The ability of the IAT neutron detector to be used to measure the "ship effect" (neutron spallation caused by cosmic rays in material near a detector) was tested by placing a box of lead bricks next to the detector. For the ship effect measurements the lead bricks were left in a wooden crate on the ground and the detector was positioned with the side containing $38 \mathrm{~mm}$ of polyethylene against the crate of bricks, as shown in Figure 5.5. The crate contained 35 lead bricks, each $51 \times 102 \times 203 \mathrm{~mm}^{3}$, for a total of $437.5 \mathrm{~kg}$ of lead. A background measurement was performed with the detector on the ground at a distance of about $3 \mathrm{~m}$ from the lead.

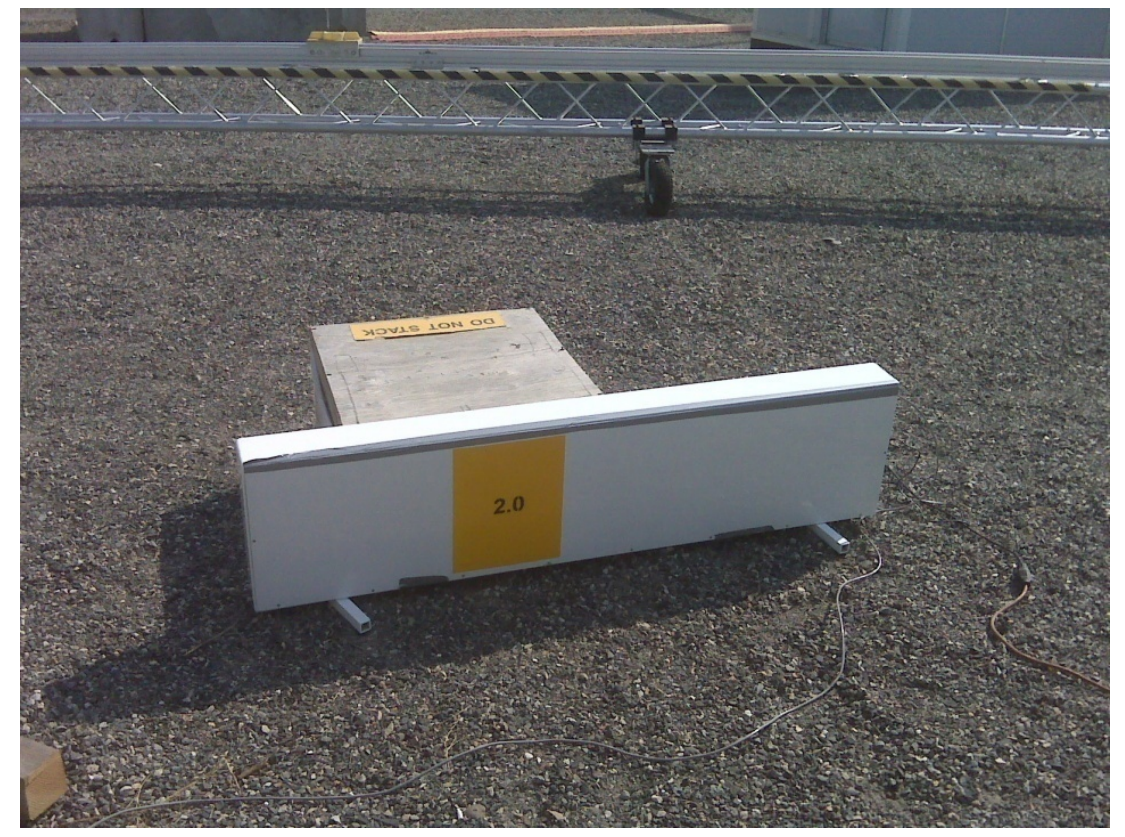

Figure 5.7: IAT detector and positioned next to lead bricks for ship effect measurements. 


\section{Results and Data Analysis}

\subsection{Static Test}

The data were collected using the IAT system software provided by the vendor. The data derived from the static tests were an average number of cps calculated over the five-minute data acquisition time. The original IAT software settings were not altered for any of the tests. Backgrounds were acquired and subsequently subtracted from each test configuration to provide the net count rate. The uncertainty in the absolute values obtained was dominated by the uncertainty in the neutron source strengths.

The net counts per second obtained with the bare and moderated neutron source for the original $38 \mathrm{~mm}$ and $51 \mathrm{~mm}$ of polyethylene moderator are plotted in Figure 6.1. Uncertainties are smaller than the markers. The net count rates obtained with the source in front of the side of the detector with $38 \mathrm{~mm}$ of moderation were higher than the net count rates obtained with the source in front of the side of the detector with $51 \mathrm{~mm}$ of moderation. This suggests that $51 \mathrm{~mm}$ of polyethylene over-moderates the detector.

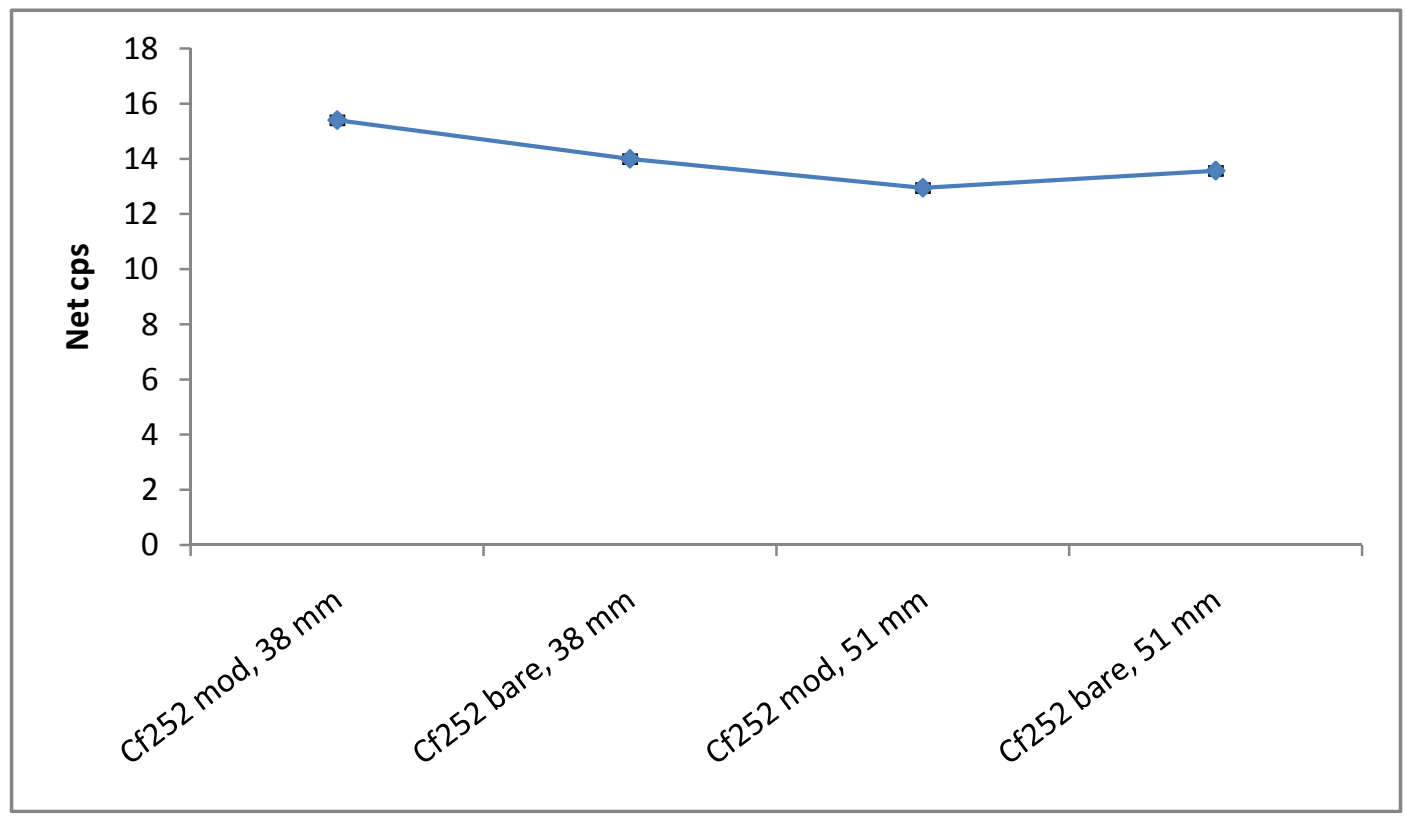

Figure 6.1: Average cps for the two original detector moderation configurations, 38 and $51 \mathrm{~mm}$, with both the moderated and bare neutron source.

The system response with varying amounts of moderation is shown in Figure 6.2. Uncertainties are smaller than the markers. The back of the detector had the original $38 \mathrm{~mm}$ of moderation for each of the front moderation thicknesses tested. The highest number of cps recorded was obtained with $28.6 \mathrm{~mm}$ of detector moderation on the front face of the detector and the moderated neutron source. The difference between the cps recorded with the bare and moderated neutron source decreased as the amount of moderation in front of the detector increased, as expected. 


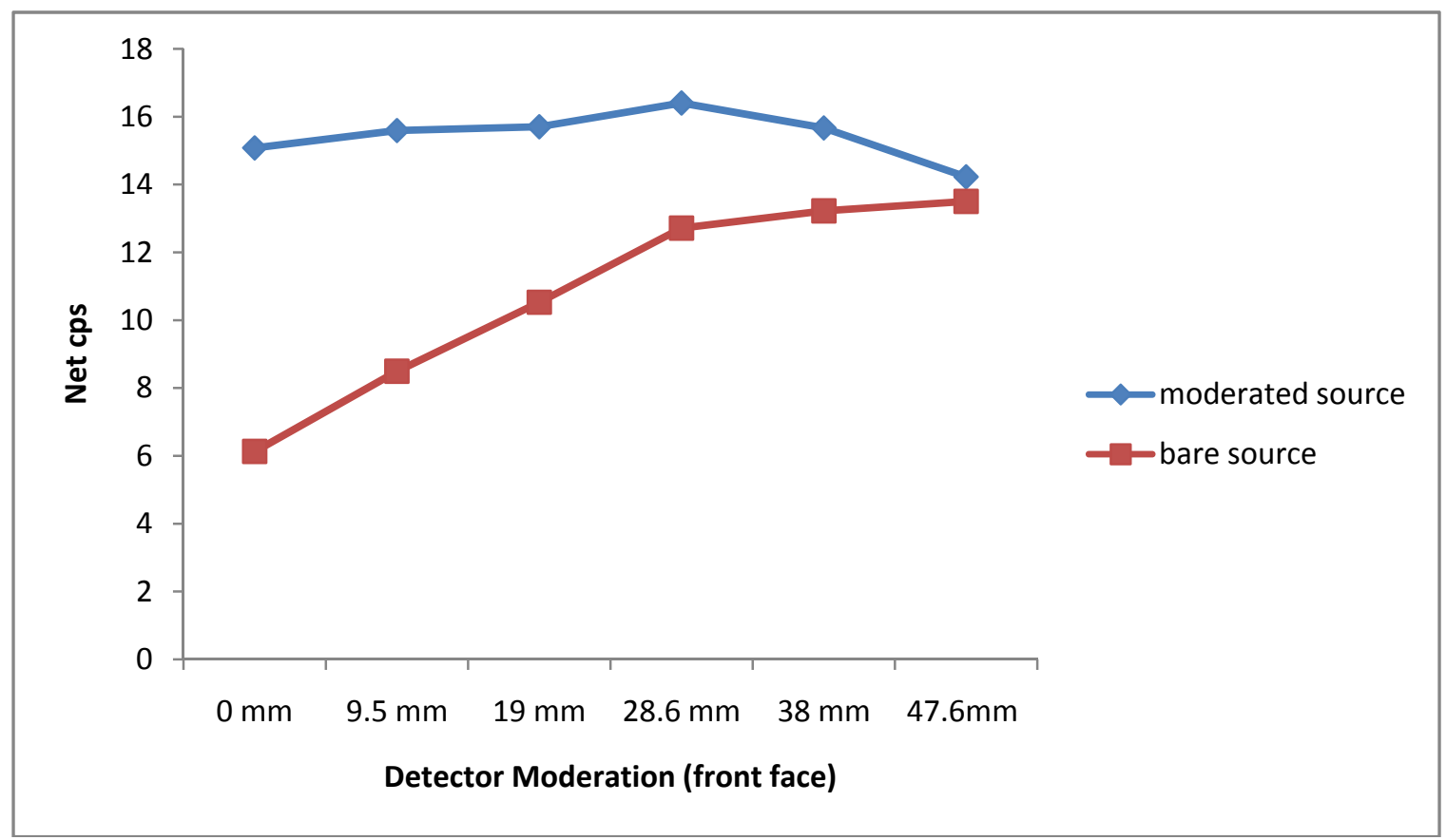

Figure 6.2: Net cps with the moderated and bare neutron source for varying amounts of moderation.

An estimation of the IAT detector efficiency was made by dividing the net count rate from each moderator configuration by the material mass (in nanograms) of the ${ }^{252} \mathrm{Cf}$ source. The results are shown unaltered and scaled by a geometric factor (x5) in Figure 6.3. Uncertainties, dominated by the source uncertainty, are shown. The scaled results account for the fact that the surface area of the IAT detector is less than the surface area of the polyethylene box in the standard ${ }^{3} \mathrm{He}$-based system. Scaling the efficiency allows for a more accurate direct comparison of the IAT detector efficiency to the standard ${ }^{3} \mathrm{He}$-based system efficiency. The performance of the standard ${ }^{3} \mathrm{He}$-based system is shown as the point at the right, and the line is simply to guide the eye. The maximum achievable absolute efficiency attained with the different moderator thicknesses was $0.50 \mathrm{cps} / \mathrm{ng}$. The increase in the IAT detector surface area by a factor of 5 will result in an area that is still less than the standard ${ }^{3} \mathrm{He}$-based polyethylene moderator box surface area, however it is the largest IAT surface area expected to fit into each standard ${ }^{3} \mathrm{He}-$ based RSP while still reserving space for associated electronics with the current design.

The predicted IAT maximum detector size would result in an absolute neutron detection efficiency of $2.51 \mathrm{cps} / \mathrm{ng}{ }^{252} \mathrm{Cf}$, achieved with $28.6 \mathrm{~mm}$ of detector moderation on the front side of the detector. The scaled efficiency is still lower than one ${ }^{3} \mathrm{He}$ tube in the SAIC ${ }^{3} \mathrm{He}$-based moderating box, which has an efficiency of $3.25 \mathrm{cps} / \mathrm{ng}{ }^{252} \mathrm{Cf}$, but exceeds the required efficiency in the PNNL specification of 2.5 $\mathrm{cps} / \mathrm{ng}$. The uncertainty shown in the figure is a result of the $\sim 10 \%$ source activity uncertainty; the uncertainty associated with the un-scaled efficiency measurements is less than the size of the markers on the plot. A larger IAT system will have to be tested to ensure that the system efficiency increases linearly with surface area. 


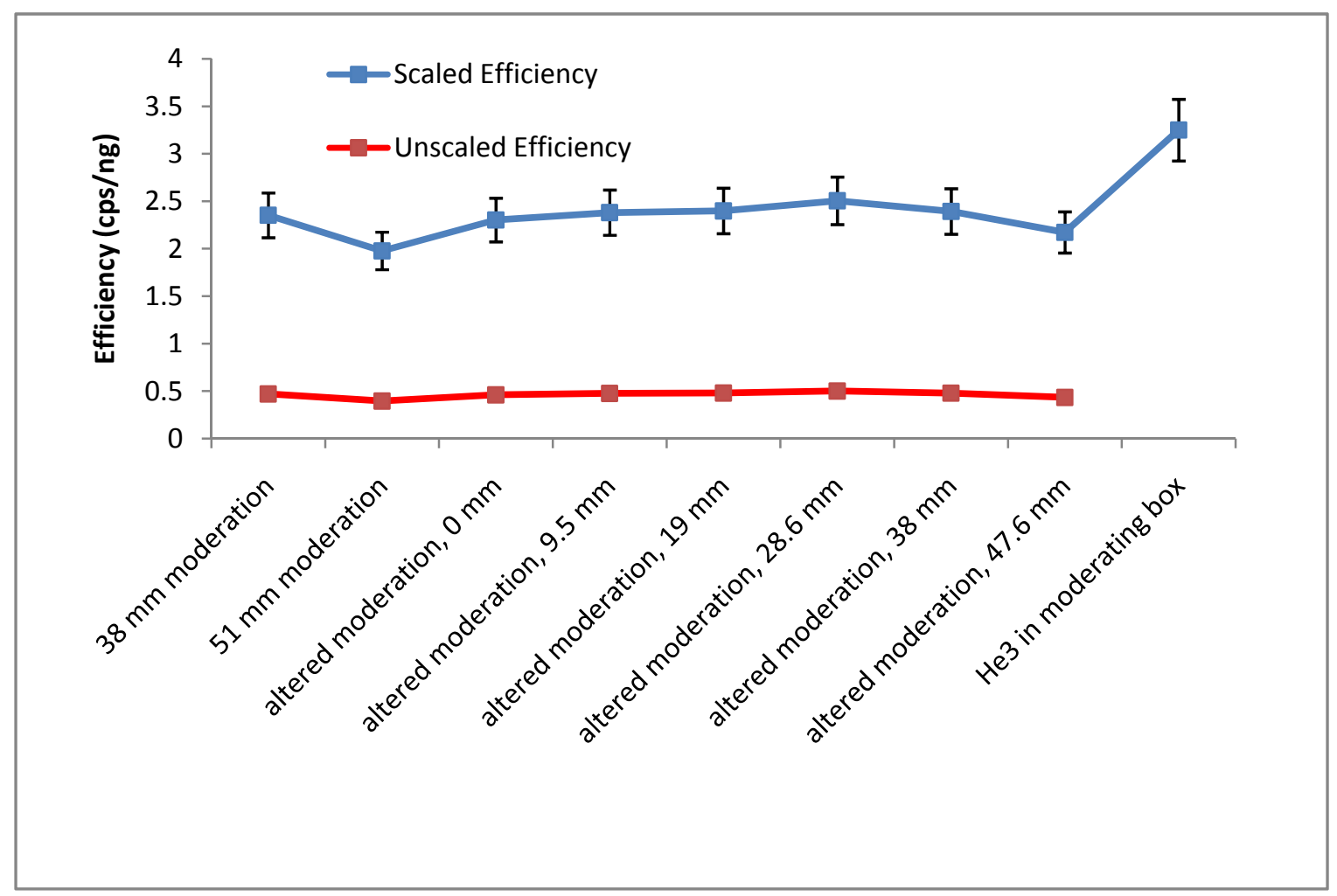

Figure 6.3: Detector efficiency shown both for the system tested and scaled by a factor of 5 compared to one ${ }^{3}$ He tube case.

\subsection{Dynamic Test}

The dynamic runs were performed with the source shuttle positioned $1 \mathrm{~m}$ from the IAT detector and $2 \mathrm{~m}$ from the front panel of the standard ${ }^{3} \mathrm{He}$-based RPM. This geometry increased the number of counts at the IAT detector by a factor of approximately four compared to the ${ }^{3} \mathrm{He}$ tube in the standard ${ }^{3} \mathrm{He}-\mathrm{based}$ system. However, a factor of five increase in the IAT active area is the size that can likely be accommodated in the currently deployed system. Thus, the results of the IAT system were scaled by a factor of $5 / 4$ to provide results that would be approximately equal to what would be achieved with a full size system.

Ten runs were made for each source and speed combination resulting in 20 passes of the shuttle by the detector. The data from each pass were shifted so that the peak occurred in the same channel and the results were averaged to reduce variations from individual runs. The standard ${ }^{3} \mathrm{He}$-based software has a time resolution of 0.1 seconds while the IAT software has a time resolution of 1 second. Therefore 10 ${ }^{3} \mathrm{He}$ data points were summed for every IAT data point to provide a comparison between the systems of the number of counts recorded each second. The peaks were shifted so that they lined up in approximately the same position. The average of the summed counts was plotted as a function of time. When the presence sensors of the SAIC system are broken, it saves data starting 5 seconds prior to the break and extending 2 seconds after the sensor connection is re-established. For this experiment, the shuttle did not stay out of the sensors long enough between runs to prevent the SAIC system from recording the previous pass. Thus, several seconds of standard ${ }^{3} \mathrm{He}$-based data could not be used which reduced the amount of data available to be plotted. The shape of the peaks appears to be similar but additional data would need to be obtained before a more complete analysis could be made. The IAT 
detector, scaled for the geometry of a larger detector (x5) and for the distance from the source (x1/4), appears to record approximately one half as many neutrons as the standard ${ }^{3} \mathrm{He}$-based system. The lower number of counts recorded in the IAT system then what was expected is due in part to the fact that the IAT system only reports data once per second, while the source moves 2.9 feet $(0.9 \mathrm{~m})$ per second at 2 mph and 7.3 feet $(2.2 \mathrm{~m})$ per second at $5 \mathrm{mph}$, decreasing the averaged counts accumulated when averaged over one second. The detector being placed closer to the shuttle also increases the effect of the changing solid angle of the detector with source position. These are examples of dynamic profiles, and uncertainties are difficult to assign. Because the two systems had different solid angles, a direct comparison cannot be made. Results for the $2.2 \mathrm{~m} / \mathrm{s}$ (Figure 6.4) and the $0.9 \mathrm{~m} / \mathrm{s}$ (Figure 6.5) runs with the moderated source are shown.

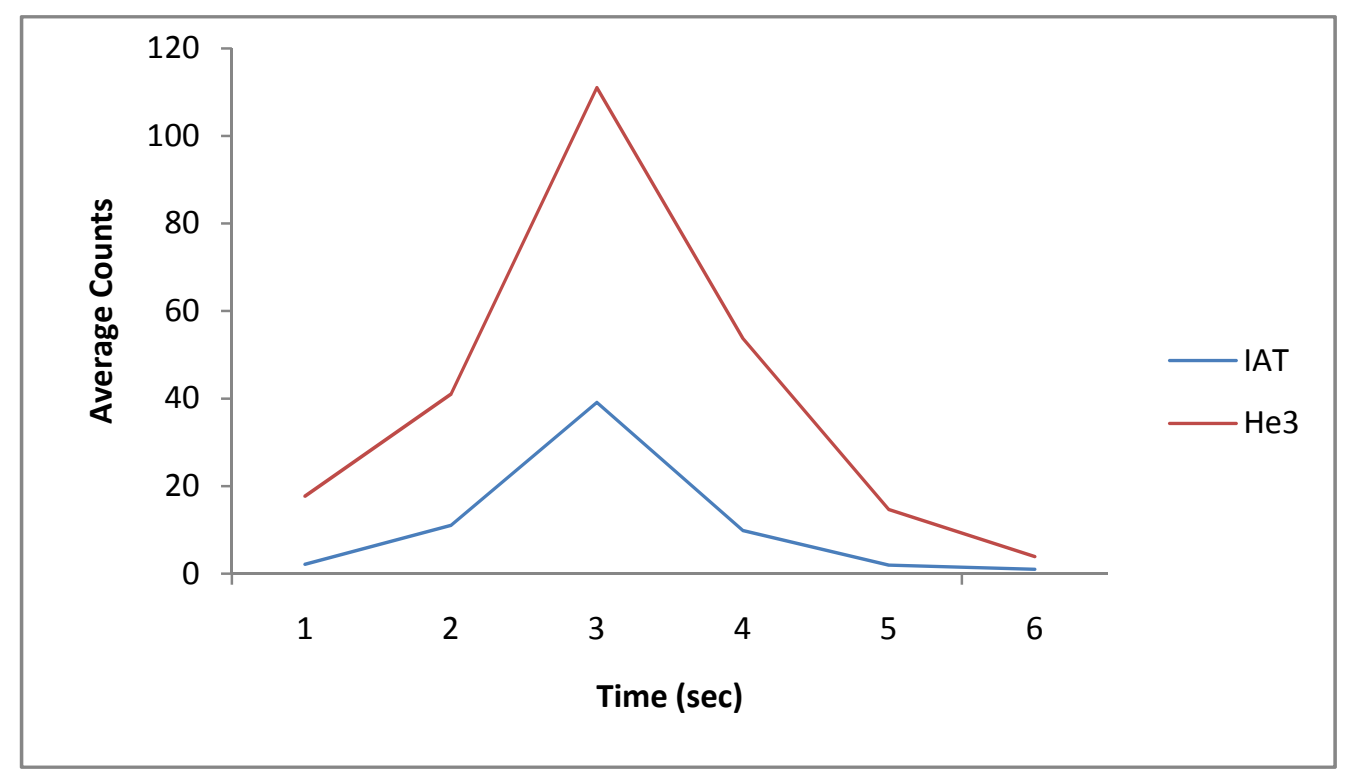

Figure 6.4: Five mph $(2.2 \mathrm{~m} / \mathrm{s})$ temporal spectra acquired with the moderated source. The ${ }^{3} \mathrm{He}$ data is summed into 1-second segments and the IAT data is scaled for geometry. 


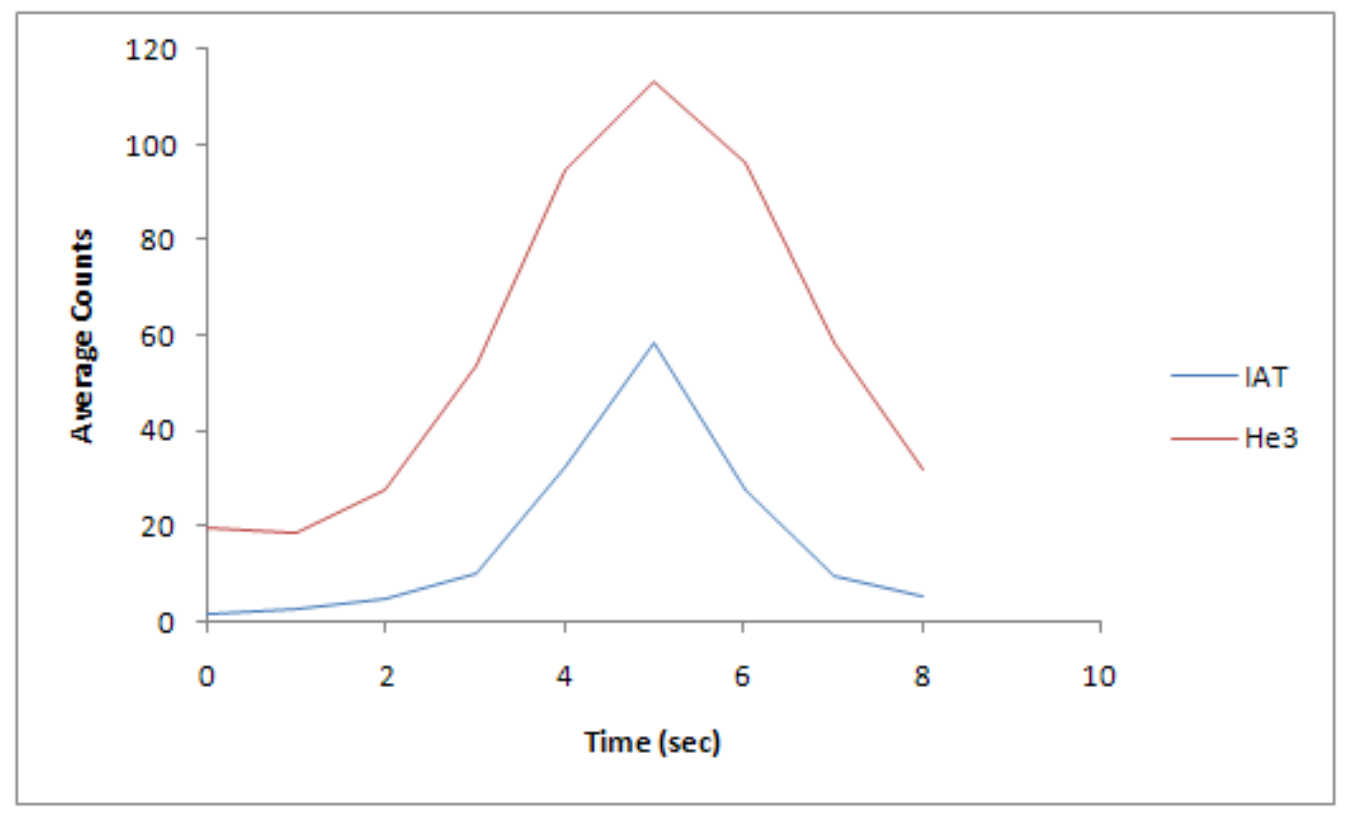

Figure 6.5: Two mph $(0.9 \mathrm{~m} / \mathrm{s})$ temporal spectra acquired with the moderated source. The ${ }^{3}$ He counts are summed into 1-second time intervals and the IAT counts are scaled for geometry.

\subsection{Gamma Insensitivity Test}

The detector sensitivity to gamma rays was tested both with gamma ray button sources placed on the detector housing and with high activity ${ }^{192} \mathrm{Ir}$ and ${ }^{60} \mathrm{Co}$ sources flooding the entire detector active area with a high exposure rate gamma field.

\section{Localized Insensitivity Measurements}

The exposure rates on the detector resulting from the ${ }^{60} \mathrm{Co}$ and the ${ }^{109} \mathrm{Cd}$ sources used for the localized gamma insensitivity measurements are shown in Table 6.1. The left and right positions correspond to the source being placed over the light guides on the right and left sides of the detector moderator.

Table 6.1: Exposure rates on the detector from the gamma sources used for location specific gamma-ray response (Knoll 2002; HPS 2009).

\begin{tabular}{|c|c|c|c|c|c|c|}
\hline Source & $\begin{array}{c}\text { Activity } \\
\mathbf{( m C i )}\end{array}$ & $\begin{array}{c}\text { Gamma Factor } \\
\left(\mathbf{R}^{*} \mathbf{c m}^{\mathbf{2}} \mathbf{h} \mathbf{h} * \mathbf{m C i}\right)\end{array}$ & $\begin{array}{c}\text { Front Face } \\
\mathbf{( R / h r})\end{array}$ & Top (R/hr) & Left (R/hr) & $\begin{array}{c}\text { Right } \\
(\mathbf{R} / \mathbf{h r})\end{array}$ \\
\hline${ }^{60} \mathrm{Co}$ & 0.0617 & 13.2 & 0.0561 & 0.1262 & 0.0389 & 0.0389 \\
\hline${ }^{109} \mathrm{Cd}$ & 1.8476 & 1.86 & 0.2367 & 0.5327 & 0.1644 & 0.1644 \\
\hline
\end{tabular}

The detector response to the gamma sources in the different positions is shown in Figure 6.6.

Approximate uncertainties are shown. All of the measurements (excluding the ones where the source was placed on top of the detector and the one where the source was placed directly on the fibers) were made on the side of the detector with $38 \mathrm{~mm}$ of polyethylene. The largest response to the gamma sources resulted when the ${ }^{60} \mathrm{Co}$ source was placed directly on the detector fibers; however even the largest change was less than $0.12 \mathrm{cps}$ (net). The response was higher for the ${ }^{109} \mathrm{Cd}$ source than the ${ }^{60} \mathrm{Co}$ source, which was not unexpected given the difference in source activities $(1.85 \mathrm{mCi}$ and $61.69 \mu \mathrm{Ci}$ respectively). For the ${ }^{60} \mathrm{Co}$ source placed directly on the fibers, the gamma rejection ratio (number of gamma rays 
misidentified as neutrons divided by the number of incident gamma rays) was $5 \times 10^{-8}$, but this was only for a localized source, not a uniform exposure of the entire detector.

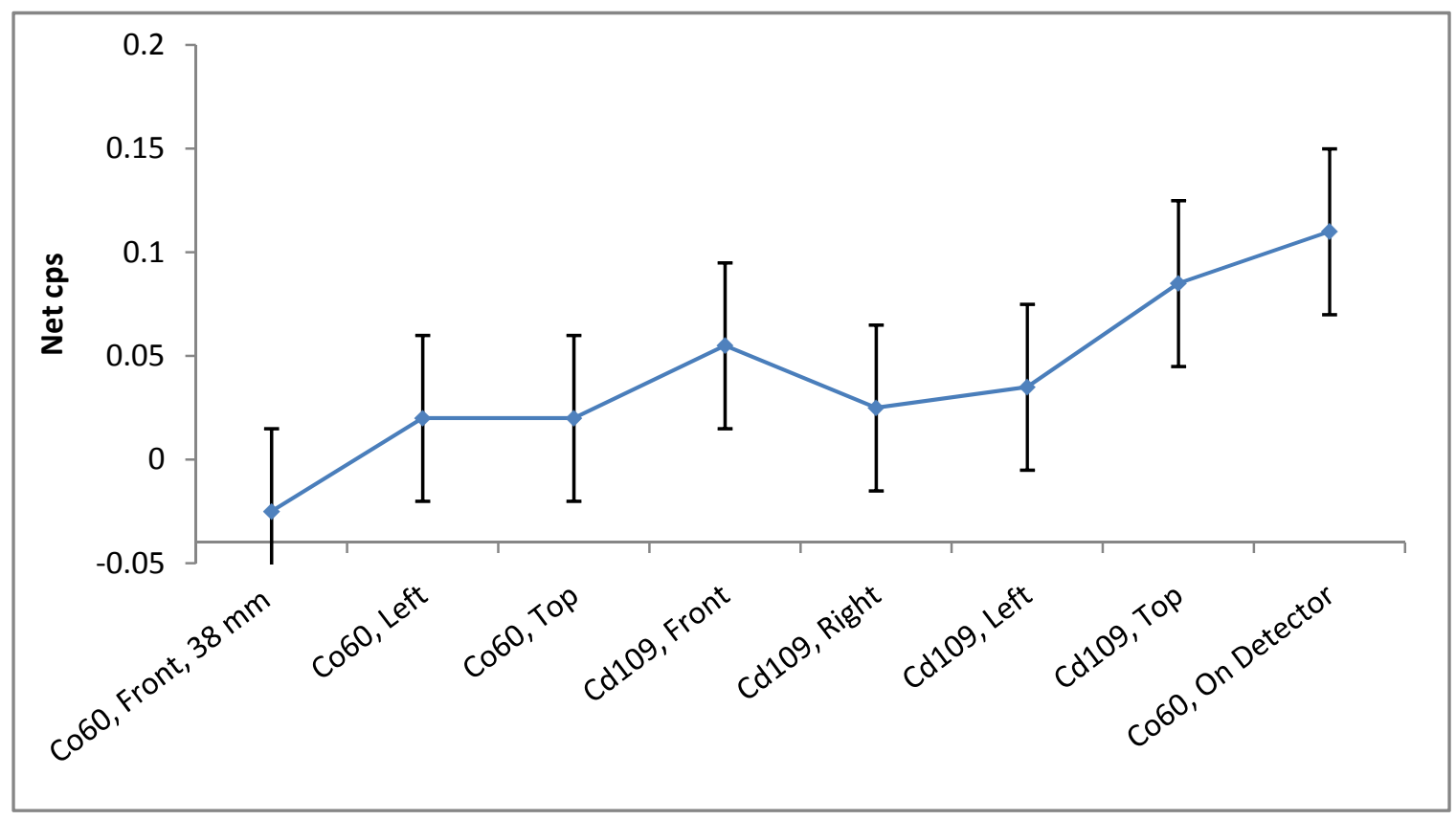

Figure 6.6: Detector response to gamma ray sources placed on the detector housing.

The ${ }^{60} \mathrm{Co}$ source (located in contact with the detector's housing box) was used simultaneously with the $17.68 \mu \mathrm{Ci}$ neutron source to determine how the detector would respond to neutrons in the presence of gamma-rays, Figure 6.7. Uncertainties are smaller than the markers. Measurements were made on both sides of the detector, and with the ${ }^{252} \mathrm{Cf}$ source moderated on one side and un-moderated on the other.

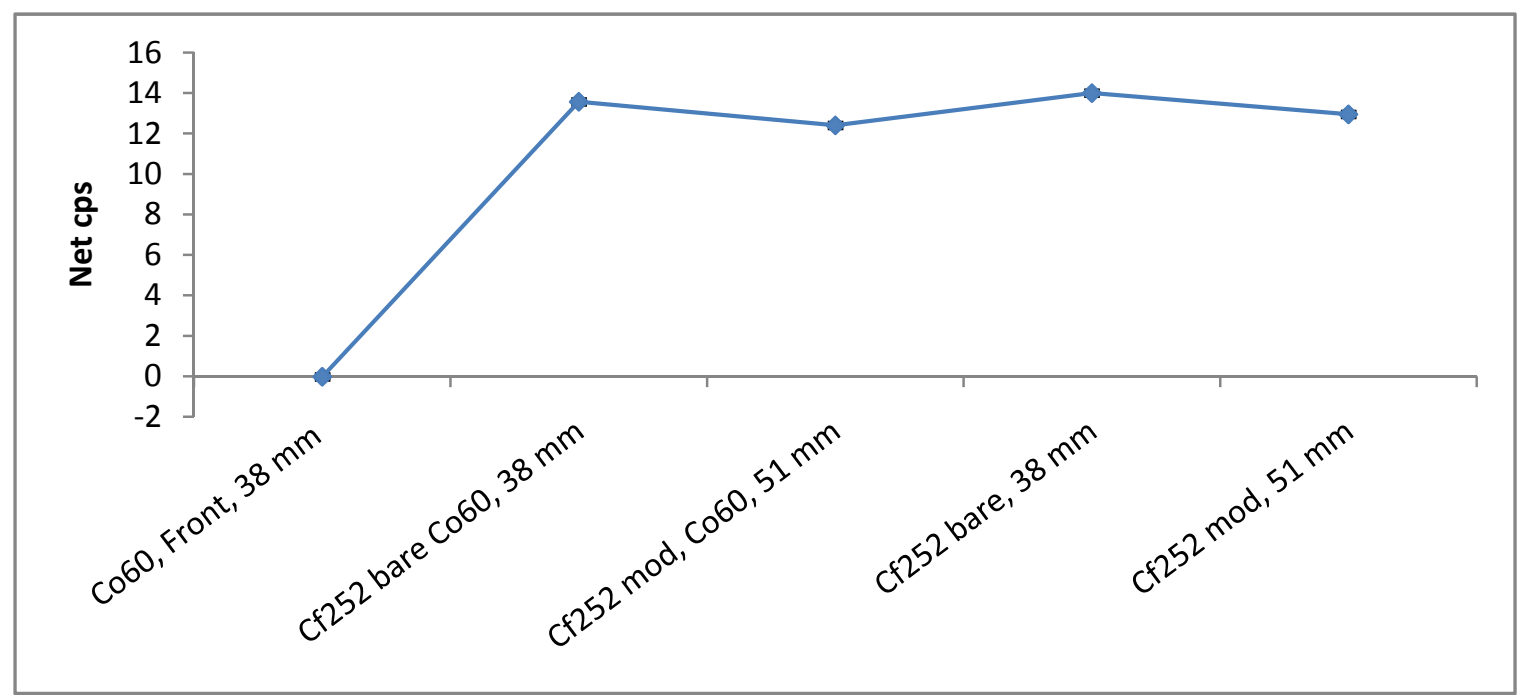

Figure 6.7: Detector response to neutrons when the ${ }^{60} \mathrm{Co}$ source was placed directly on the detector housing. 


\section{High Exposure Rate Insensitivity Measurements}

The detector response to a high dose rate was tested using the ${ }^{192} \mathrm{Ir}$ and the ${ }^{60} \mathrm{Co}$ sources. Data were collected over five minute intervals for the four different scenarios (background, gamma source, gamma source with ${ }^{252} \mathrm{Cf}$ and just ${ }^{252} \mathrm{Cf}$ ). The two different sources were used for the high gamma exposure rate measurements because the activity required to reach the desired exposure rate is different for sources with different energy gamma emissions. Thus, comparing the detector response from the different sources will demonstrate if the system has the same response to the same exposure rate from different sources.

\section{${ }^{192}$ Ir Insensitivity Measurements}

For exposure rates of $20 \mathrm{mR} / \mathrm{hr}$ and below from the ${ }^{192} \mathrm{Ir}$ source there was a decrease in the number of neutron counts recorded by the IAT detector suggesting that the detector experiences some dead time in the presence of a gamma field. The largest net decrease observed was $0.75 \mathrm{cps}$ and occurred with an exposure rate of $20 \mathrm{mR} / \mathrm{hr}$, as seen in Table 6.2. Exposure rates of $40 \mathrm{mR} / \mathrm{hr}$ and above indicate the gamma pile-up mimics the neutron pulse shape in the detector, as can be seen in the neutron (after pulse shape discrimination) pulse height spectra acquired in the presence of different gamma exposure rates (Figure 6.9). The pile up events caused by the high gamma exposure rates result in increased neutron counts being recorded, as listed in Table 6.2.

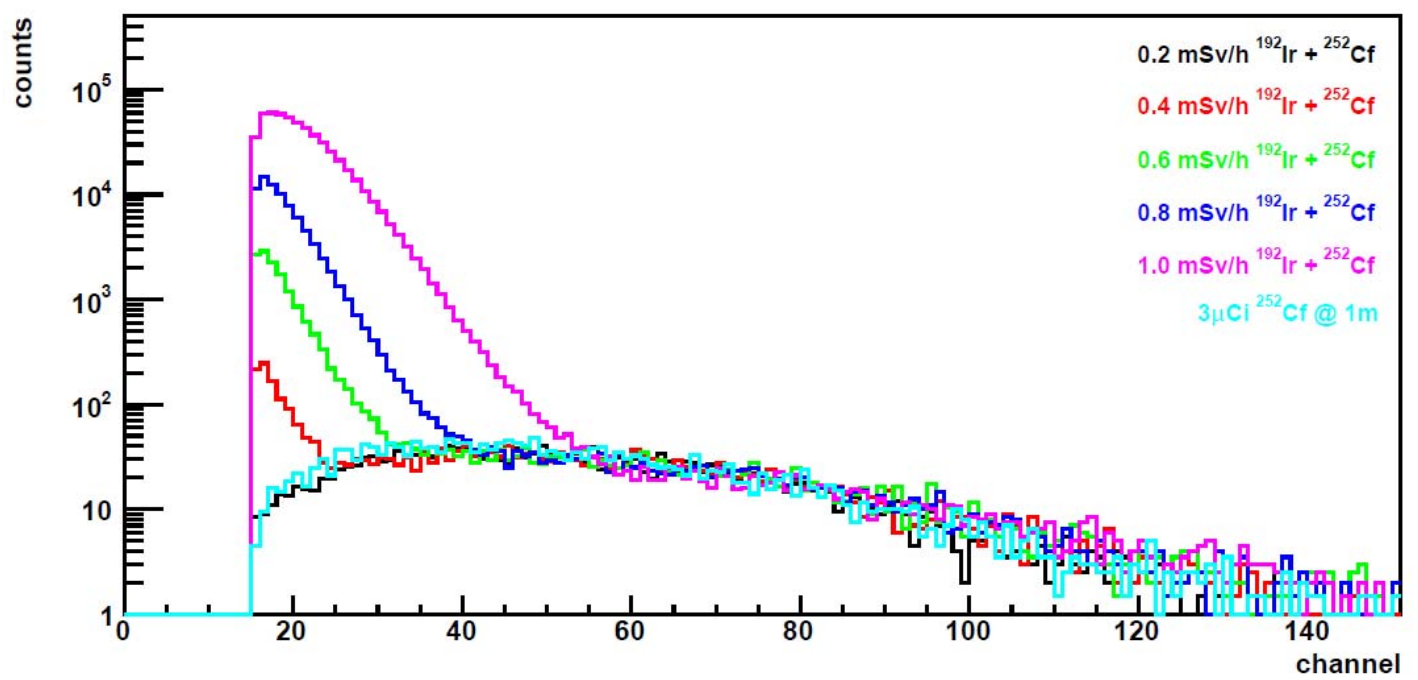

Figure 6.8: Pulse height spectra of the IAT neutron detector in response to a neutron source and a gamma field of different exposure rates compared to the pulse height spectra from a neutron source without the gamma source.

Table 6.2: Neutron counts recorded in the presence of a high exposure rate gamma field from ${ }^{192}$ Ir.

\begin{tabular}{|c|c|c|c|c|}
\hline $\begin{array}{c}\text { Exposure } \\
\text { Rate } \\
\text { (mR/hr) }\end{array}$ & $\begin{array}{l}\text { Neutron Counts } \\
\text { with only }{ }^{192} \mathrm{Ir} \\
\text { Source (net cps) }\end{array}$ & $\begin{array}{l}4.5 \mu \mathrm{Ci}{ }^{252} \mathrm{Cf} \\
\text { Source Only } \\
\text { (net cps) }\end{array}$ & $\begin{array}{l}\text { Neutron Counts with } \\
{ }^{252} \mathrm{Cf} \text { and }{ }^{192} \mathrm{Ir} \\
\text { Sources (net cps) }\end{array}$ & $\begin{array}{c}\left({ }^{252} \mathrm{Cf} \text { Source) minus }\right. \\
\left({ }^{252} \mathrm{Cf} \&{ }^{192} \mathrm{Ir} \text { Sources) }\right. \\
\text { (net cps) }\end{array}$ \\
\hline 10 & 0.02 & 6.82 & 6.54 & 0.28 \\
\hline 15 & 0.04 & 6.76 & 6.58 & 0.18 \\
\hline 20 & 0.01 & 6.95 & 6.20 & 0.75 \\
\hline 40 & 3.11 & 7.09 & 9.41 & -2.32 \\
\hline 60 & 47.38 & 7.14 & 51.78 & -44.64 \\
\hline 80 & 275.98 & 7.31 & 262.65 & -255.34 \\
\hline 100 & 1836.83 & 7.01 & 1841.94 & -1834.93 \\
\hline
\end{tabular}


The detector's ability to discriminate between neutrons and gammas is limited to exposure rates below $\sim 20 \mathrm{mR} / \mathrm{hr}$ with the current hardware and software settings. An approximate value for the efficiencies and GARRn can be calculated by developing an estimate of the gamma flux at the detector.

\section{${ }^{192}$ Ir Gamma Flux Estimate}

The photon flux at the detector was estimated using the source strength and the exposure rate measurements. Scaling the source strength $(18 \mathrm{Ci})$ by the square of the distance from the detector to the source and using the average value of 2.1265 gammas per decay provides an approximate flux on the detector. The flux can then be scaled to determine the number of gammas incident on the active surface area of the detector $(0.25 \mathrm{~m} \times 0.25 \mathrm{~m})$. However, this method does not account for any attenuation by the air or scattering from the ground or air. An alternative approach is to calculate an effective activity using the measured exposure rate at the detector and the gamma factor for ${ }^{192} \operatorname{Ir}\left(5.8 \mathrm{R}^{*} \mathrm{~cm}^{2} / \mathrm{hr} \mathrm{mCi}\right)$. The effective activity is the source activity that would be required to produce the measured exposure rate at the distance from the source the detector was located. The effective activity can then be used to calculate the flux on the detector's active surface area identically to how the flux was calculated with the actual source activity. A comparison of these two methods is shown in Table 6.3. The two methods show good agreement in the estimated number of photons on the detector for each position. The unusual behavior of the effective source strength values at high dose rates arises from the scattering and absorption effects.

Table 6.3: Estimated number of ${ }^{192}$ Ir photons incident on the active area of the detector calculated using both the source strength and an effective activity for each of the exposure rates.

\begin{tabular}{|c|c|c|c|c|}
\hline $\begin{array}{c}\text { Exposure Rate } \\
(\mathbf{m R} / \mathbf{h r})\end{array}$ & $\begin{array}{c}\text { Detector to } \\
\text { Source Distance } \\
(\mathbf{m})\end{array}$ & $\begin{array}{c}\text { Estimated } \\
\text { Photons on } \\
\text { Detector From } \\
\text { Source Strength } \\
\mathbf{( c p s )}\end{array}$ & $\begin{array}{c}\text { 'Effective' Source } \\
\text { Activity (Ci) }\end{array}$ & $\begin{array}{c}\text { Estimated } \\
\text { Photons on } \\
\text { Detector From } \\
\text { Effective Activity } \\
\text { (cps) }\end{array}$ \\
\hline 10 & 29.2 & $8.25 \mathrm{E}+06$ & 14.7 & $6.74 \mathrm{E}+06$ \\
\hline 15 & 27.4 & $9.38 \mathrm{E}+06$ & 19.4 & $1.01 \mathrm{E}+07$ \\
\hline 20 & 24.6 & $1.16 \mathrm{E}+07$ & 20.9 & $1.35 \mathrm{E}+07$ \\
\hline 40 & 18.2 & $2.13 \mathrm{E}+07$ & 22.9 & $2.70 \mathrm{E}+07$ \\
\hline 60 & 14.6 & $3.30 \mathrm{E}+07$ & 22.1 & $4.06 \mathrm{E}+07$ \\
\hline 80 & 12.3 & $4.66 \mathrm{E}+07$ & 20.9 & $5.40 \mathrm{E}+07$ \\
\hline 100 & 9.5 & $7.80 \mathrm{E}+07$ & 15.6 & $6.76 \mathrm{E}+07$ \\
\hline 200 & 7.5 & $1.25 \mathrm{E}+08$ & 19.4 & $1.35 \mathrm{E}+08$ \\
\hline
\end{tabular}

\section{${ }^{60}$ Co Insensitivity Measurements}

For exposure rates of $20 \mathrm{mR} / \mathrm{hr}$ and below with the ${ }^{60} \mathrm{Co}$ and ${ }^{252} \mathrm{Cf}$ sources, there was a decrease in the number of neutron counts recorded by the IAT detector compared to the ${ }^{252} \mathrm{Cf}$ source alone, supporting the results obtained with the ${ }^{192} \mathrm{Ir}$ source that the detector experiences some dead time in the presence of the gamma field. The largest decrease observed was $2 \mathrm{cps}$ and occurred with an exposure rate of 20 $\mathrm{mR} / \mathrm{hr}$, as seen in Table 6.4. Exposure rates of $30 \mathrm{mR} / \mathrm{hr}$ and above show pile up in the detector. The pile up events caused by the high gamma exposure rates result in increased neutron counts being recorded, as shown in Table 6.4. There is a larger neutron count rate suppression observed with the ${ }^{60}$ Co source compared to the ${ }^{192} \mathrm{Ir}$ source but the increase in the neutron count rate at high exposure rates is less with the ${ }^{60} \mathrm{Co}$ source than with the ${ }^{192} \mathrm{Ir}$ source. 
The detector's ability to discriminate between neutrons and gammas with a ${ }^{60}$ Co source is limited to exposure rates below $\sim 30 \mathrm{mR} / \mathrm{hr}$ with the current settings. As was done with the ${ }^{192} \mathrm{Ir}$ source an approximate value for the efficiencies and GARRn can be calculated by developing an estimate of the gamma flux at the detector.

Table 6.4: Neutron counts recorded in the presence of a high exposure rate ${ }^{60} \mathrm{Co}$ gamma field.

\begin{tabular}{|c|c|c|c|c|}
\hline $\begin{array}{l}\text { Exposure } \\
\text { Rate } \\
(\mathrm{mR} / \mathrm{hr})\end{array}$ & $\begin{array}{l}\text { Neutron Counts } \\
\text { with only }{ }^{60} \mathrm{Co} \\
\text { Source (net cps) }\end{array}$ & $\begin{array}{l}17.68 \mu \mathrm{Ci} \\
{ }^{252} \mathrm{Cf} \text { Source } \\
\text { Only (net } \\
\text { cps) }\end{array}$ & $\begin{array}{l}\text { Neutron Counts with } \\
{ }^{252} \mathrm{Cf} \text { and }{ }^{60} \mathrm{Co} \\
\text { Sources (net cps) }\end{array}$ & $\begin{array}{c}\left({ }^{252} \mathrm{Cf} \text { Source) minus }\right. \\
\left({ }^{252} \mathrm{Cf} \&{ }^{60} \mathrm{Co} \mathrm{Sources}\right) \\
\text { (net cps) }\end{array}$ \\
\hline 10 & 0.01 & 16 & 14 & 2 \\
\hline 20 & 0.50 & 16 & 14 & 2 \\
\hline 30 & 3.2 & 16 & 17 & -1 \\
\hline 40 & 12 & 15 & 25 & -10 \\
\hline 50 & 31 & 15 & 45 & -30 \\
\hline 70 & 114 & 15 & 126 & -111 \\
\hline 100 & 383 & 15 & 398 & -383 \\
\hline
\end{tabular}

\section{${ }^{60}$ Co Gamma Flux Estimate}

The exact source strength for these measurements was not known, and as the measurements were made indoors scatter was assumed to be a larger contributing factor to any source strength calculation. Thus, the gamma flux at the detector was estimated using the effective activity which was calculated as with the ${ }^{192}$ Ir source by using the measured exposure rate at the detector, 2 gammas per decay, and the gamma factor for ${ }^{60} \mathrm{Co}\left(13.2 \mathrm{R}^{*} \mathrm{~cm}^{2} / \mathrm{hr} * \mathrm{mCi}\right)$. The effective activity is defined as the source activity that would be required to produce the measured exposure rate at the distance from the source the detector was located. The effective activity was used to calculate the flux on the detector's active surface area in the same manner as if it were the actual activity of the source. The results are shown in Table 6.5.

Table 6.5: Estimated number of photons incident on the active area of the detector calculated using the effective activity for each of the exposure rates.

\begin{tabular}{|c|c|c|c|}
\hline $\begin{array}{c}\text { Exposure Rate } \\
(\mathbf{m R} / \mathbf{h r})\end{array}$ & $\begin{array}{c}\text { Detector to } \\
\text { Source Distance } \\
\mathbf{( m )}\end{array}$ & $\begin{array}{c}\text { 'Effective' Source } \\
\text { Activity (Ci) }\end{array}$ & $\begin{array}{c}\text { Estimated } \\
\text { Photons on } \\
\text { Detector From } \\
\text { Effective Activity } \\
\text { (cps) }\end{array}$ \\
\hline 10 & 3.88 & 0.114 & $2.79 \mathrm{E}+06$ \\
\hline 20 & 2.74 & 0.114 & $5.59 \mathrm{E}+06$ \\
\hline 30 & 2.24 & 0.114 & $8.37 \mathrm{E}+06$ \\
\hline 40 & 1.94 & 0.114 & $1.12 \mathrm{E}+07$ \\
\hline 50 & 1.73 & 0.136 & $1.40 \mathrm{E}+07$ \\
\hline 70 & 1.47 & 0.131 & $1.94 \mathrm{E}+07$ \\
\hline 100 & 1.23 & 0.115 & $2.78 \mathrm{E}+07$ \\
\hline
\end{tabular}

\section{Gamma Insensitivity Measurement Results}

A value for the intrinsic gamma ray efficiency and GARRn can be estimated using the calculated photon flux and the un-scaled neutron efficiency. The neutron efficiency used to calculate GARRn for each 
gamma exposure was the efficiency associated with each particular measurement. Thus, any geometrical effects are divided out of the results.

The IAT detector tested has intrinsic gamma ray efficiencies $\left(\epsilon_{\text {int } \gamma \mathrm{n}}\right)$ on the order of $10^{-9}$ for ${ }^{192} \mathrm{Ir}$ exposure rates up to $40 \mathrm{mR} / \mathrm{hr}$ and on the order of $10^{-8}$ for ${ }^{60} \mathrm{Co}$ exposure rates up to $30 \mathrm{mR} / \mathrm{hr}$. The intrinsic gamma ray efficiency for ${ }^{192}$ Ir was calculated by taking the ratio of column two from Table 6.2 (the number of neutron counts recorded in the presence of only a gamma ray source) and the average of columns three and five from Table 6.3 (the number of photons incident on the detector). The intrinsic gamma efficiency with ${ }^{192} \mathrm{Ir}$ for this small detector is similar to ${ }^{3} \mathrm{He}$ (Ely et al., 2009) at $40 \mathrm{mR} / \mathrm{hr}$ and it is better than the required $10^{-6}$ value for an exposure rate of $10 \mathrm{mR} / \mathrm{hr}$. For ${ }^{60} \mathrm{Co}$ the intrinsic gamma ray efficiency was calculated by taking the ratio of column two from Table 6.4 and column four from Table 6.5 and is below the required value of $10^{-6}$ for a $10 \mathrm{mR} / \mathrm{hr}$ exposure rate. The GARRn value for ${ }^{192} \mathrm{Ir}$ at $10 \mathrm{mR} / \mathrm{hr}$ is within the desired window $(0.9 \leq$ GARRn $\leq 1.1)$, however the GARRn value for ${ }^{60} \mathrm{Co}$ is $0.89(1)$ at $10 \mathrm{mR} / \mathrm{hr}$, which is one standard deviation outside of the desired window. The GARRn values for exposure rates above $10 \mathrm{mR} / \mathrm{hr}$ indicate that there is a loss of neutron efficiency and/or an increase in count rate from gamma rays when the detector is exposed to high gamma exposures, as shown in Table 6.6. GARRn was calculated by taking the ratio of column four to column three in Table 6.2 for ${ }^{192}$ Ir and Table 6.4 for ${ }^{60} \mathrm{Co}$. Although more ${ }^{192}$ Ir photons then ${ }^{60} \mathrm{Co}$ photons are required to produce the same exposure rate the detector produces a larger response to the ${ }^{60} \mathrm{Co}$ source. The ${ }^{60} \mathrm{Co}$ source is higher energy then the ${ }^{192} \mathrm{Ir}$ source, thus the ${ }^{60} \mathrm{Co}$ Compton interactions result in more deposited energy in the fibers that increases the potential for multiple interactions and thus pileup. These results indicate that the IAT detector may have adequate gamma ray insensitivity to allow use in fielded systems but there is some loss of neutron efficiency in the presence of high gamma exposure rates. However, testing of a full size unit will be required before this capability will be fully known.

Table 6.6: Estimates of the Absolute Efficiency, GARRn and the Intrinsic Gamma Ray Rejection Factor for the different gamma exposure rates for the small detector tested.

\begin{tabular}{|c|c|c|c|c|c|c|}
\hline $\begin{array}{c}\text { Exposure } \\
\text { Rate } \\
(\mathrm{mR} / \mathrm{hr})\end{array}$ & $\begin{array}{c}\text { Neutron } \\
\text { Efficiency } \\
\left({ }^{192} I r\right) \\
C_{n}\end{array}$ & $\begin{array}{c}\text { Neutron } \\
\text { Efficiency } \\
\left({ }^{60} \mathrm{Co}\right) \\
\mathrm{C}_{\mathrm{n}}\end{array}$ & $\begin{array}{c}\text { Intrinsic } \\
\text { Gamma Ray } \\
\text { Efficiency } \\
\left({ }^{192} \text { Ir }\right) \\
\epsilon_{\text {int } \gamma \mathbf{n}}\end{array}$ & $\begin{array}{c}\text { GARRn } \\
\left({ }^{192} \mathrm{Ir}\right) \\
\mathbf{C}_{\mathrm{abs} \gamma \mathrm{n}} / \mathbf{\epsilon}_{\mathrm{n}}\end{array}$ & $\begin{array}{c}\text { Intrinsic } \\
\text { Gamma Ray } \\
\text { Efficiency } \\
\left({ }^{60} \mathrm{Co}\right) \\
\mathbf{C}_{\text {int } \gamma \mathrm{n}}\end{array}$ & $\begin{array}{c}\text { GARRn } \\
\left({ }^{60} \mathrm{Co}\right) \\
\mathbf{\epsilon}_{\text {abs } \gamma \mathbf{n}} / \mathbf{\epsilon}_{\mathrm{n}}\end{array}$ \\
\hline 10 & 0.072 & 0.189 & $2.7 \times 10^{-9}$ & $0.96(2)$ & $3.6 \times 10^{-9}$ & $0.89(1)$ \\
\hline 15 & 0.071 & - & $2.6 \times 10^{-9}$ & $0.97(2)$ & - & - \\
\hline 20 & 0.073 & 0.189 & $8.0 \times 10^{-10}$ & $0.89(2)$ & $8.9 \times 10^{-8}$ & $0.90(1)$ \\
\hline 30 & - & 0.189 & - & - & $3.9 \times 10^{-7}$ & $1.04(1)$ \\
\hline 40 & 0.074 & 0.180 & $1.3 \times 10^{-7}$ & $1.33(3)$ & $1.0 \times 10^{-6}$ & $1.62(2)$ \\
\hline 50 & - & 0.180 & - & - & $2.2 \times 10^{-6}$ & $2.90(3)$ \\
\hline 60 & 0.075 & - & $1.3 \times 10^{-6}$ & $7.25(13)$ & - & - \\
\hline 70 & - & 0.180 & - & - & $5.9 \times 10^{-6}$ & $8.18(9)$ \\
\hline 80 & 0.077 & - & $5.5 \times 10^{-6}$ & $37.0(6)$ & - & - \\
\hline 100 & 0.073 & 0.180 & $2.5 \times 10^{-5}$ & $263(4)$ & $1.4 \times 10^{-5}$ & $25.8(3)$ \\
\hline
\end{tabular}

\subsection{Ship Effect Measurements}

Data were collected over a five-minute time interval with the lead bricks next to the detector to record the increase in the rate of recorded neutrons. The average neutron count rate recorded, with the lead bricks in place, was $0.55 \mathrm{cps}$ higher than what was recorded for background (which was $0.61 \mathrm{cps}$ ). The background for this experiment was recorded when the detector was on the ground about $3 \mathrm{~m}$ from the lead. 
The ship effect measurements were not intended to provide comparison data with other types of detectors. Instead, they illustrate the known effect that proximity to significant amounts of lead (or steel or other dense materials) can produce measurable neutrons that exceed background rates.

Additional data were acquired using the "Oscope" feature in the IAT software that provides an image of the pulses recorded by the detector in one-second intervals. The Oscope allowed single, double, and triple neutron event images to be recorded, as seen in Figure 6.9. These images demonstrated the presence of multiple neutron detections occurring within a few microseconds of each other. The spallation events occur in the ship effect gives off neutrons within a few nanoseconds, but the moderation time spreads the neutrons out into the microsecond regime.

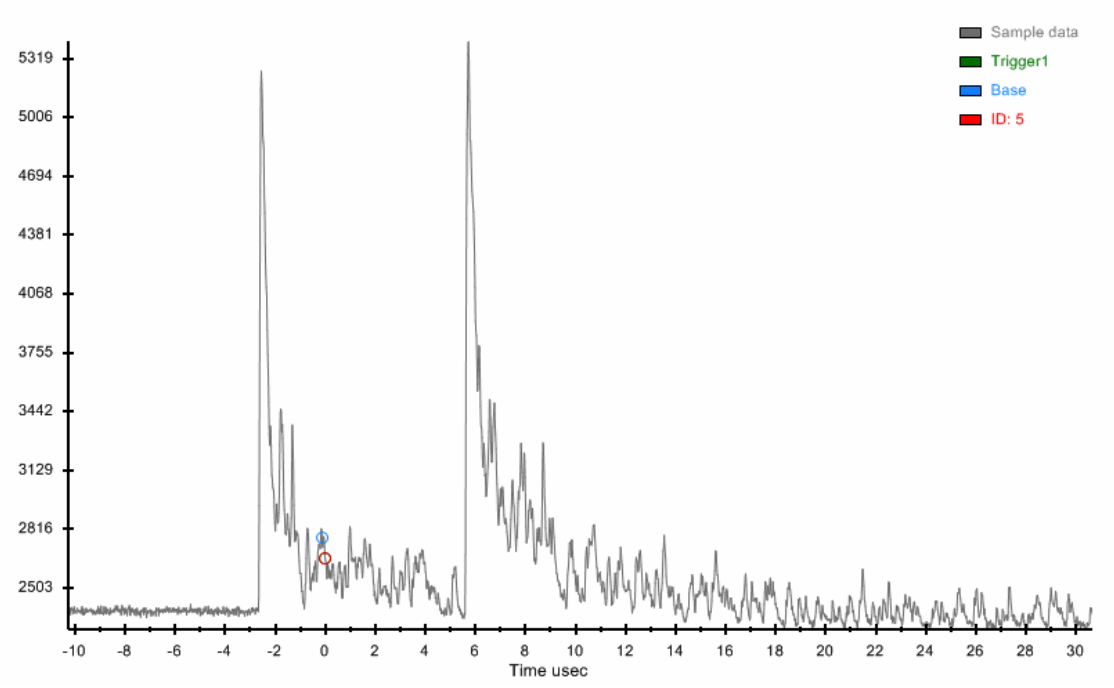

(a)

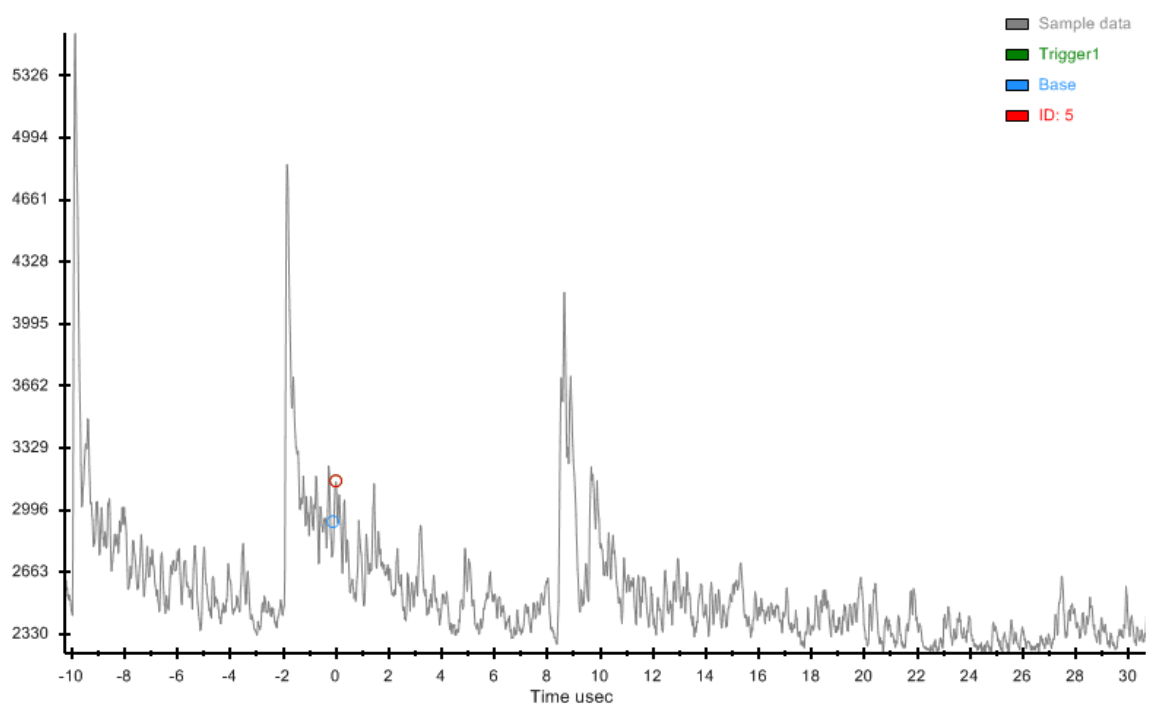

(b)

Figure 6.9: Simultaneously recorded double neutron event (a) and triple neutron event (b) due to the ship effect. Images recorded using the IAT Oscope software. 


\section{Conclusions}

The IAT detection system has been tested and compared to ${ }^{3} \mathrm{He}$ as a possible alternative neutron detection technology. The IAT detector uses plastic fibers that are coated with ${ }^{6} \mathrm{Li} / \mathrm{ZnS}(\mathrm{Ag})$ to detect neutrons. Discrimination between neutrons and gamma rays is based on pulse shape.

The tests were conducted on an IAT detector with a surface area of $0.25 \mathrm{~m} \mathrm{x} 0.25 \mathrm{~m}$. Results suggest that neutron detection efficiency comparable to existing ${ }^{3} \mathrm{He}$ detectors will be obtained if the detector's size is scaled up to occupy the available space of the present neutron detector system in the standard ${ }^{3} \mathrm{He}-\mathrm{based}$ RPM, assuming linear scaling. The additional electronics required for the IAT detector will likely limit the size increase to a factor of about five to six from what was tested in these measurements. Larger IAT systems will need to be tested to determine if there is a significant loss of efficiency in scaling up due to such effects as attenuation in longer fibers.

Test results indicate that adequate intrinsic gamma ray efficiency (gamma ray rejection) is obtained for gamma exposure rates below approximately $40 \mathrm{mR} / \mathrm{hr}$ for the small detector tested. The gamma rejection factor is estimated to be on the order of $10^{-7}$ for a dose rate of $40 \mathrm{mR} / \mathrm{hr}$ from an ${ }^{192} \mathrm{Ir}$ source, which is close to that obtained for ${ }^{3} \mathrm{He}\left(\sim 10^{-8}\right)$. There is a slightly larger response to the ${ }^{60} \mathrm{Co}$ gamma source with the gamma rejection factor estimated to be about $10^{-6}$ for the IAT neutron detector while it is $10^{-9}$ for ${ }^{3} \mathrm{He}$ tubes. Measurements will need to be made to determine if the gamma rejection capability is retained when the detector is scaled up in size. However, it seems likely that the intrinsic gamma ray efficiency of the larger IAT neutron detector will meet the required value of $10^{-6}$ in a $10 \mathrm{mR} / \mathrm{hr}$ field.

The GARRn value at a ${ }^{60} \mathrm{Co}$ exposure rate of $10 \mathrm{mR} / \mathrm{hr}$ is within one standard deviation of the desired range, indicating that there is some miscounting of neutrons in the presence of large gamma exposure rates. The small system tested thus does not quite meet this requirement for ${ }^{60} \mathrm{Co}$, but does for the ${ }^{192} \mathrm{Ir}$ source. Testing of a larger system designed for use as a replacement for the ${ }^{3} \mathrm{He}$ based system in deployed systems will need to be evaluated to see whether the GARRn value is in an acceptable range.

The current software of the IAT detector limits the temporal resolution attainable for dynamic measurements to 1 second. It is suspected that increasing the readout rate would improve the dynamic sensitivity of the IAT system. However, even with this software change, modifications of the standard ${ }^{3} \mathrm{He}$-based hardware and software would be necessary to use the IAT detector as a replacement for ${ }^{3} \mathrm{He}$ tubes.

The "oscope" software feature was successfully used to record simultaneous neutron events caused by the ship effect in $437.5 \mathrm{~kg}$ of lead placed near the detector. The net increase in count rate was $0.55 \mathrm{cps}$.

The cost of the tested unit was $\sim \$ 20 \mathrm{k}$, though this unit price should decrease when production is increase. 


\section{References}

ANSI. 2004. American National Standard for Evaluation and Performance of Radiation Detection Portal Monitors for Use in Homeland Security. Technical Report. ANSI 42.35, American Nuclear Standards Institute, Washington, D.C.

ASP. 2006. U.S. Department of Homeland Security Domestic Nuclear Detection Office (DNDO), Performance Specification for an Advanced Spectroscopic Portal (ASP), DNDO-PS-100220v2.20, March 15, 2006.

Ely J, Kouzes RT, Lintereur A, Schweppe J, Siciliano E, and Woodring M. 2009. BF 3 Neutron Detector Testing and Comparison to ${ }^{3} \mathrm{He}$. PNNL-18581, Pacific Northwest National Laboratory, Richland, Washington.

Ely J, D Stromswold, and C Shepard. 2003. Radiation Portal Monitor Measurements. PIET-43741-TM014, PNNL-14110, Pacific Northwest National Laboratory, Richland, Washington.

Kouzes RT, Ely J, Lintereur A, Stephens D. 2009. Neutron Detector Gamma Insensitivity Criteria. PNNL -18903, Pacific Northwest National Laboratory, Richland, Washington.

Ely J and C Shepard. 2004. Test and Evaluation of the SAIC/Exploranium RPM8 Portal Monitor System. PIET-43741-TM-161, PNNL-16865, Pacific Northwest National Laboratory, Richland, Washington.

HPS 2009. Accessed at http://hpschapters.org/northcarolina/nuclide_information_library September 2009. ISO-8529. 1989. International Organization for Standardization 8529.

Kiernan G. 2003. Gerald Kiernan to Todd Hoffman, "Gamma and Neutron Sources for Use at Land Border, Seaport, and Airport Venues (U)," classified (SNSI) second guidance document from DOE/NA22, February 28, 2003 (PNNL received a copy of this document on June 17, 2003). Update of DOE guidance document to CBP of September 19, 2002.

Knoll GF. 2002. Radiation Detection and Measurement $3^{\text {rd }}$ Ed. John Wiley and Sons, New York.

Kouzes RT, J Ely, and E Siciliano. 2007. Neutron Alarm Algorithms for Deployed RPMs. PIET-43741TM-663, PNNL-17101, Pacific Northwest National Laboratory, Richland, Washington.

Kouzes, RT, JH Ely, PE Keller, RJ McConn, and ER Siciliano. 2008. "Passive Neutron Detection for Interdiction of Nuclear Material at Borders." Nuclear Instruments and Methods in Physics Research Section A: Accelerators, Spectrometers, Detectors and Associated Equipment 584(2-3): 383-400.

Kouzes RT, ER Siciliano. 2009. ${ }^{3}$ He Neutron Detector Modification and BF $F_{3}$ Comparison. PIET-43741TM-838, PNNL-xxx, Pacific Northwest National Laboratory, Richland, Washington.

Kouzes, RT, 2009. “The ${ }^{3}$ He Supply Problem," Pacific Northwest National Laboratory Report PNNL18388.

MCNP. 2003. MCNP X-5 Monte Carlo Team, MCNP - A General Purpose Monte Carlo N-Particle Transport Code, Version 5, LA-UR-03-1987, Los Alamos National Laboratory, April 2003. The MCNP code can be obtained from the Radiation Safety Information Computational Center (RSICC), P.O. Box 2008, Oak Ridge, TN, 37831-6362.

NNDC. National Nuclear Data Center. Accessed June 12, 2009 at http://www.nndc.bnl.gov/index.jsp.

Stromswold D, J Ely, R Kouzes, J Schweppe. 2003. Specifications for Radiation Portal Monitor Systems Revision 6.7. PIET-43741-TM-017, Pacific Northwest National Laboratory, Richland, Washington. 
Van Ginhoven, RM, RT Kouzes, DL Stephens, 2009. “Alternative Neutron Detector Technologies for Homeland Security,” Pacific Northwest National Laboratory Report PNNL-18471. 


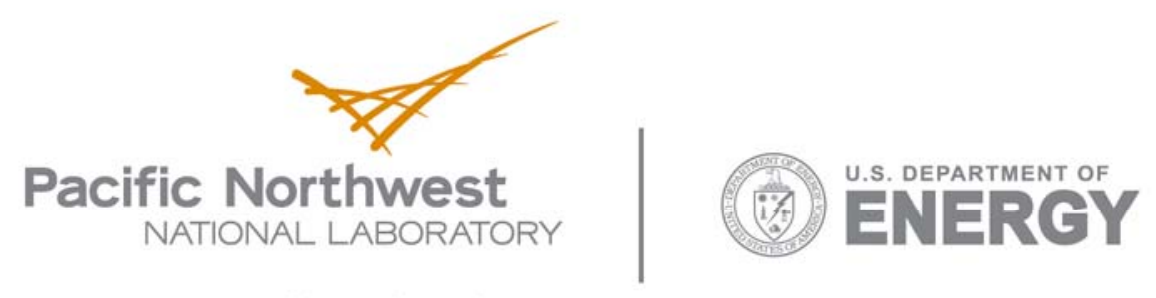

902 Battelle Boulevard

P.O. Box 999

Richland, WA 99352

1-888-375-PNNL (7665)

www.pnl.gov 